\title{
Two-dimensional carbon nitride (2DCN) nanosheets: Tuning of novel electronic and magnetic properties by hydrogenation, atom substitution and defect engineering
}

Cite as: J. Appl. Phys. 126, 215104 (2019); https://doi.org/10.1063/1.5120525

Submitted: 22 July 2019 . Accepted: 09 November 2019 . Published Online: 02 December 2019

Asadollah Bafekry (D), Saber Farjami Shayesteh (D), and Francois M. Peeters (D)

\section{COLLECTIONS}

Paper published as part of the special topic on Defects in Semiconductors 2020

Note: This paper is part of the Special Topic on Defects in Semiconductors 2020.
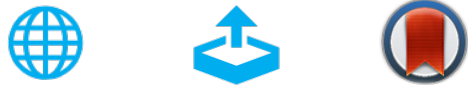

\section{ARTICLES YOU MAY BE INTERESTED IN}

Optimization of Seebeck coefficients of strain-symmetrized semiconductor heterostructures Applied Physics Letters 115, 211602 (2019); https://doi.org/10.1063/1.5123294

\section{Carbon pair defects in aluminum nitride}

Journal of Applied Physics 126, 215102 (2019); https://doi.org/10.1063/1.5123049

Mechanical properties of monolayer ternary transitional metal dichalogenides $\operatorname{MoS}_{2 x} \operatorname{Te}_{2(1-x)}$ : A molecular dynamics study

Journal of Applied Physics 126, 215105 (2019); https://doi.org/10.1063/1.5122264

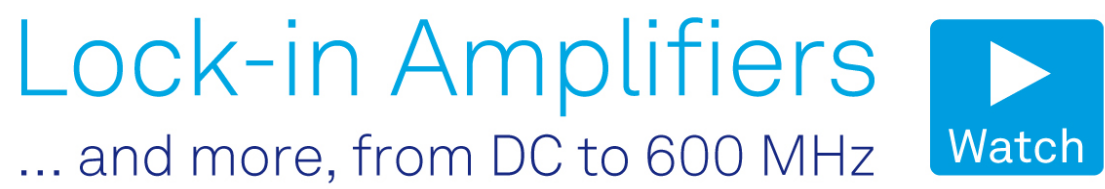




\title{
Two-dimensional carbon nitride (2DCN) nanosheets: Tuning of novel electronic and magnetic properties by hydrogenation, atom substitution and defect engineering
}

Cite as: J. Appl. Phys. 126, 215104 (2019); doi: 10.1063/1.5120525

Submitted: 22 July 2019 . Accepted: 9 November 2019 .

Published Online: 2 December 2019

Asadollah Bafekry, ${ }^{1,2, a)}$ (iD Saber Farjami Shayesteh, ${ }^{1}$ (D) and Francois M. Peeters ${ }^{2}$ (iD)

AFFILIATIONS

${ }^{1}$ Department of Physics, University of Guilan, 41335-1914 Rasht, Iran

${ }^{2}$ Department of Physics, University of Antwerp, Groenenborgerlaan 171, B-2020 Antwerp, Belgium

Note: This paper is part of the Special Topic on Defects in Semiconductors 2020.

${ }^{a)}$ Author to whom correspondence should be addressed: Asadollah.Bafekry.@uantwerpen.be

\begin{abstract}
By employing first-principles calculations within the framework of density functional theory, we investigated the structural, electronic, and magnetic properties of graphene and various two-dimensional carbon-nitride (2DNC) nanosheets. The different $2 \mathrm{DCN}$ gives rise to diverse electronic properties such as metals $\left(\mathrm{C}_{3} \mathrm{~N}_{2}\right)$, semimetals $\left(\mathrm{C}_{4} \mathrm{~N}\right.$ and $\left.\mathrm{C}_{9} \mathrm{~N}_{4}\right)$, half-metals $\left(\mathrm{C}_{4} \mathrm{~N}_{3}\right)$, ferromagnetic-metals $\left(\mathrm{C}_{9} \mathrm{~N}_{7}\right)$, semiconductors $\left(\mathrm{C}_{2} \mathrm{~N}, \mathrm{C}_{3} \mathrm{~N}, \mathrm{C}_{3} \mathrm{~N}_{4}, \mathrm{C}_{6} \mathrm{~N}_{6}\right.$, and $\left.\mathrm{C}_{6} \mathrm{~N}_{8}\right)$, spin-glass semiconductors $\left(\mathrm{C}_{10} \mathrm{~N}_{9}\right.$ and $\left.\mathrm{C}_{14} \mathrm{~N}_{12}\right)$, and insulators $\left(\mathrm{C}_{2} \mathrm{~N}_{2}\right)$. Furthermore, the effects of adsorption and substitution of hydrogen atoms as well as $\mathrm{N}$-vacancy defects on the electronic and magnetic properties are systematically studied. The introduction of point defects, including $\mathrm{N}$ vacancies, interstitial $\mathrm{H}$ impurity into graphene and different $2 \mathrm{DCN}$ crystals, results in very different band structures. Defect engineering leads to the discovery of potentially exotic properties that make $2 \mathrm{DCN}$ interesting for future investigations and emerging technological applications with precisely tailored properties. These properties can be useful for applications in various fields such as catalysis, energy storage, nanoelectronic devices, spintronics, optoelectronics, and nanosensors.
\end{abstract}

Published under license by AIP Publishing. https://doi.org/10.1063/1.5120525

\section{INTRODUCTION}

Recently, a special class of two-dimensional materials (2DM), made from carbon and nitrogen atoms, has attracted much attention due to their outstanding physical and chemical properties. Layered nanomaterials solely composed of $\mathrm{C}$ and $\mathrm{N}$ atoms, with the ability of $\mathrm{N}$ atoms to take many different positions, enhance the possibilities to form strong covalent networks. These features allow to grow an extensive number of graphenic carbon-nitride lattices. Two-dimensional carbon-nitride (2DCN) allotropes show a common chemical formula $\mathrm{C}_{n} \mathrm{~N}_{m}$, where $n$ and $m$ represent the number of $\mathrm{C}$ and $\mathrm{N}$ atoms in the primitive lattice, respectively. 2DCN nanomaterials are well known to exhibit strong and stable components, owing to the formation of covalent bonds between the $\mathrm{C}-\mathrm{C}$ and $\mathrm{C}-\mathrm{N}$ bonds. For different compositions and configurations of the $\mathrm{C}$ and $\mathrm{N}$ atoms, these nanomaterials can exhibit diverse and promising electronic, optical, mechanical, and thermal properties. 2DCN shows attractive bandgaps and offers surface engineering possibilities and are well known to have interesting application prospects in both energy- and environment-related topics, including catalysts, photocatalysis, and hydrogen evolution. ${ }^{1-7}$

A few decades ago, $2 \mathrm{DCN}$ with the chemical formula $\mathrm{C}_{3} \mathrm{~N}_{4}$ was synthesized. ${ }^{3}$ Unlike graphite, $2 \mathrm{DCN}$ shows porous atomic lattices and more importantly are inherent semiconductors. ${ }^{8}$ Very recently, $2 \mathrm{D}$ nitrogenated holey graphene with $\mathrm{C}_{2} \mathrm{~N}$ stoichiometry was experimentally fabricated via a wet-chemical reaction. ${ }^{9} \mathrm{C}_{2} \mathrm{~N}$, which contains an evenly distributed lattice of $\mathrm{N}$ and hole sites, makes it an excellent candidate as a nanofilter and an interesting structure for the adsorption of atoms and molecules. ${ }^{9,11}$ Recently, Mahmood et al., reported the first experimental realization of 2D polyaniline with stoichiometric formula $\mathrm{C}_{3} \mathrm{~N}$ and a graphenelike 
TABLE I. The structural, electronic, and magnetic parameters of graphene and 2DCN nanosheets; including lattice constant a; the bond length between $\mathrm{C}-\mathrm{C}$ atoms $\left(d_{\mathrm{C}}-\mathrm{C}\right)$; the bond length between $\mathrm{C}-\mathrm{N}$ atoms $\left(d_{C-N}\right)$; the diameter of nanopore $D_{N P}$ and the bandgap $\left(E_{g}\right)$. Electronic state is specified as metal $(M)$, semimetal $(S M)$, half-metal (HM), insulator (INS), spin-glass semiconductor (SG-SC), direct semiconductor (SC-di), and indirect semiconductor (SC-ind). The magnetic moment per supercell $M_{\text {tot }}$ is also given.

\begin{tabular}{|c|c|c|c|c|c|c|c|}
\hline $2 \mathrm{DCN}$ & $\mathrm{a}(\AA)$ & $\mathrm{E}_{F}(\mathrm{eV})$ & $d_{\mathrm{C}-\mathrm{C}}(\AA)$ & $d_{\mathrm{C}-\mathrm{N}}(\AA)$ & $\mathrm{D}_{N P}(\AA)$ & $E_{g}(\mathrm{eV})$ & $M_{t o t}\left(\mu_{B}\right)$ \\
\hline Graphene & 2.46 & 7.15 & 1.42 & $\ldots$ & $\ldots$ & SM & 0 \\
\hline $\mathrm{C}_{2} \mathrm{~N}$ & 8.345 & 7.58 & $1.457 / 1.430$ & 1.342 & 5.503 & SC (1.75)-di & 0 \\
\hline $\mathrm{C}_{3} \mathrm{~N}$ & 4.861 & 7.67 & 1.404 & 1.403 & $\ldots$ & SC (0.4)-ind & 0 \\
\hline $\mathrm{C}_{4} \mathrm{~N}$ & 4.775 & 7.83 & 1.445 & 1.443 & $\ldots$ & $\mathrm{SM}$ & 0 \\
\hline $\mathrm{C}_{2} \mathrm{~N}_{2}$ & 2.350 & 7.22 & 1.445 & 1.443 & $\ldots$ & INS (5) & 0 \\
\hline $\mathrm{C}_{3} \mathrm{~N}_{2}$ & 8.70 & 7.22 & $1.402 / 1.511$ & $1.354 / 1.392$ & $4.254,5.454$ & $\mathrm{SM}$ & 0 \\
\hline $\mathrm{C}_{3} \mathrm{~N}_{4}$ & 4.74 & 7.21 & $\ldots$ & $1.323 / 1.445$ & 2.728 & SC (1.45)-di & 0 \\
\hline $\mathrm{C}_{4} \mathrm{~N}_{3}$ & 4.81 & 7.26 & 1.427 & 1.346 & 2.736 & HM (2.2) & 1 \\
\hline $\mathrm{C}_{6} \mathrm{~N}_{6}$ & 7.11 & 7.35 & 1.503 & 1.343 & 5.447 & $\mathrm{SC}(1.5)-\mathrm{di}$ & 0 \\
\hline $\mathrm{C}_{6} \mathrm{~N}_{8}$ & 7.14 & 7.27 & $\ldots$ & $1.414 / 1.455$ & 4.773 & SC (1.22)-in & 0 \\
\hline $\mathrm{C}_{9} \mathrm{~N}_{4}$ & 9.72 & 7.60 & $1.428 / 1.470$ & $1.348 / 1.407$ & 5.588 & $\mathrm{SM}$ & 0 \\
\hline $\mathrm{C}_{9} \mathrm{~N}_{7}$ & 8.05 & 78.30 & $1.414 / 1.488$ & $1.385 / 1.444$ & 5.472 & FM & 0.8 \\
\hline $\mathrm{C}_{10} \mathrm{~N}_{9}$ & 9.86 & 7.33 & $1.418 / 1.502$ & $1.370 / 1.385$ & 7.300 & SG-SC (1.7) & 1 \\
\hline
\end{tabular}

structure in which nitrogen is uniformly distributed. ${ }^{10}$ Theoretical studies showed that $\mathrm{C}_{3} \mathrm{~N}$ exhibits ultrahigh stiffness and thermal conductivity. ${ }^{12}$ Furthermore, DFT calculations showed that the electronic properties of $\mathrm{C}_{3} \mathrm{~N}$ can be tuned by the adsorption of atoms and molecules. ${ }^{12-15}$ Like its $\mathrm{C}_{2} \mathrm{~N}$ counterparts, $\mathrm{C}_{3} \mathrm{~N}$ is also an intrinsic semiconductor according to recent theoretical studies. $\mathrm{A} \mathrm{C}_{3} \mathrm{~N}$ nanosheet can show desirable properties for different applications, like nanoelectronics, catalysis, and hydrogen storage. ${ }^{16-20}$

$\mathrm{C}_{3} \mathrm{~N}_{4}$ showed semiconducting properties with the possibility to be a potential photocatalyst for water splitting. ${ }^{21,22}$ This structure features intrinsic vacancies that are expected to produce a spinpolarized state, while the electronic property of $\mathrm{C}_{3} \mathrm{~N}_{4}$ will be drastically modified when atoms are substituted. $\mathrm{C}_{4} \mathrm{~N}_{3}$ is the counterpart of $\mathrm{C}_{3} \mathrm{~N}_{4}$ and is at present the only that has been experimentally synthesized ${ }^{23}$ and was identified to be half-metallic. ${ }^{24}$ Metal-free magnetism and half-metallicity in $\mathrm{C}_{4} \mathrm{~N}_{3}$ nanosheets and nanotubes ${ }^{25-27}$ was recently predicted to be useful in spintronic devices. Recently, $\mathrm{C}_{6} \mathrm{~N}_{6}$ has been explored in experiments ${ }^{28,29}$ and was investigated theoretically. ${ }^{30}$ It was shown that $\mathrm{C}_{6} \mathrm{~N}_{6}$ has topologically nontrivial electronic states and it can be tuned into a topological insulator by doping. ${ }^{31}$ The successful synthesis and fabrication of $\mathrm{C}_{2} \mathrm{~N}, \mathrm{C}_{3} \mathrm{~N}$, $\mathrm{C}_{6} \mathrm{~N}_{8}$, and $\mathrm{C}_{6} \mathrm{~N}_{6}$ through bottom-up procedures motivated us to consider different approaches to tune the bandgap. ${ }^{3,9,32}$

In spite of the fact that $2 \mathrm{DM}$ hold great potential for a wide range of applications, it will be necessary to modulate their intrinsic properties to transfer them into real applications. In recent years, several approaches have been developed to modify the electronic and magnetic properties of 2DM. Defects can be generated during the growth and preparation process of the nanomaterial. It is well known that defects are difficult to avoid in materials especially in 2DM, which can dramatically affect the structure, its electronic and magnetic properties, and the performance of 2DM-based devices. Defects are usually seen as detrimental to device performance. However, they also can bring about new beneficial effects on the electronic structure ${ }^{33,34}$ and expand the potential applications of
$2 \mathrm{DM}{ }^{35-38}$ Therefore, it is very important to understand the influence of these defects on their electronic and magnetic properties. Such understanding would also help in creating ideas to control defects and in this way to prepare 2DM with novel properties.

Point defects, including vacancy, impurity, and interstitial atoms, will tailor the electronic properties of $2 \mathrm{DM},{ }^{39-45,56-59}$ which can be used for a wide range of applications. ${ }^{46-55}$ While there has been limited theoretical studies, an in depth survey of trends across the range of $2 \mathrm{DCN}$ nanosheets, with various defects, is still lacking. In the present work, we first performed an extensive study of the structural, electronic, and magnetic properties of pristine $2 \mathrm{DCN}$ nanosheets including $\mathrm{C}_{2} \mathrm{~N}, \mathrm{C}_{3} \mathrm{~N}, \mathrm{C}_{4} \mathrm{~N}, \mathrm{C}_{2} \mathrm{~N}_{2}, \mathrm{C}_{3} \mathrm{~N}_{2}, \mathrm{C}_{3} \mathrm{~N}_{4}, \mathrm{C}_{4} \mathrm{~N}_{3}, \mathrm{C}_{6} \mathrm{~N}_{6}, \mathrm{C}_{6} \mathrm{~N}_{8}, \mathrm{C}_{9} \mathrm{~N}_{4}$, $\mathrm{C}_{9} \mathrm{~N}_{7}, \mathrm{C}_{10} \mathrm{~N}_{9}$, and $\mathrm{C}_{14} \mathrm{~N}_{12}$ by using first-principles calculations. In addition, we investigated the effects of point defects including vacancy, adsorption, and substitution of hydrogen on the structure, electronic, and magnetic properties of graphene and $2 \mathrm{DCN}$ nanosheets.

\section{COMPUTATIONAL METHOD}

In this paper, we performed calculations of the electronic structure with geometric optimization, using spin-polarized density functional theory (DFT) as implemented in the OpenMX Package. ${ }^{60}$ This code self-consistently finds the eigenvalues and eigenfunctions of the Kohn-Sham equations for the systems under study using norm-conserving pseudopotentials ${ }^{62}$ and pseudoatomic orbitals (PAOs). ${ }^{63,64}$ In addition, we used the Perdew-Burke-Ernzerhof generalized gradient approximation (GGA) for exchange and correlation. ${ }^{61}$ The $\mathrm{K}$ points for sampling over the Brillouin zone (BZ) were generated using the Monkhorst-Pack scheme. ${ }^{65}$ After convergence tests, we chose different energy cutoffs (for instance, $300 \mathrm{Ry}$ for $\mathrm{C}_{3} \mathrm{~N}$ ) so that the total-energy converge below $1.0 \mathrm{meV} /$ atom. In the first step, the atomic positions are optimized using a quasi-Newton algorithm for atomic force relaxation. The geometries were fully relaxed until the force acting on each atom was less than $1 \mathrm{meV} / \AA$. The Brillouin zone (BZ) is sampled by a K-mesh grid of $23 \times 23 \times 1$ 
and scaled according to the size of the supercell. The $2 \mathrm{DCN}$ is modeled as a periodic slab with a sufficiently large vacuum layer (20 ̊) in order to avoid interaction between adjacent layers. Simulated scanning tunneling microscopy (STM) images were obtained using the Tersoff-Hamann theory ${ }^{66}$ and were graphed using WSxM software. ${ }^{67}$ The formation energy per atom in a primitive unit cell was calculated using the formula $E_{F}=\left(N_{\mathrm{C}} E_{\mathrm{C}}+N_{\mathrm{N}} E_{\mathrm{N}}-E_{\mathrm{C}_{n} \mathrm{~N}_{m}}\right) /\left(N_{\mathrm{C}}+N_{\mathrm{N}}\right)$, where $E_{\mathrm{C}}$ and $E_{\mathrm{N}}$ denote the total energies of the single $\mathrm{C}$ and $\mathrm{N}$ atoms, respectively, while $E_{\mathrm{C}_{n} \mathrm{~N}_{m}}$ denotes the total energy of the different monolayers $\mathrm{C}_{n} \mathrm{~N}_{m}$. The formation energies are listed in Table I.

\section{PRISTINE 2DCN NANOSHEETS}

Geometric atomic structures of graphene and 2DCN nanosheets are shown in Fig. 1. The schematic view of 2DCN nanosheets including $\mathrm{C}_{2} \mathrm{~N}, \mathrm{C}_{3} \mathrm{~N}, \mathrm{C}_{3} \mathrm{~N}_{2}, \mathrm{C}_{3} \mathrm{~N}_{4}, \mathrm{C}_{4} \mathrm{~N}_{3}, \mathrm{C}_{6} \mathrm{~N}_{6}, \mathrm{C}_{6} \mathrm{~N}_{8}, \mathrm{C}_{9} \mathrm{~N}_{4}, \mathrm{C}_{9} \mathrm{~N}_{7}$, $\mathrm{C}_{10} \mathrm{~N}_{9}$, and $\mathrm{C}_{14} \mathrm{~N}_{12}$ with their various applications are shown in Fig. S1 (see the supplementary material). Before investigating the electronic properties, we first optimize the geometrical structure of $2 \mathrm{DCN}$. The crystal lattice parameters are listed in Table I. The variation of the total energy of the relaxed $2 \mathrm{DCN}$ as a function of the crystal lattice constant, with hexagonal and rectangular networks is shown in Fig. S2 of the supplementary material. The optimized geometry for each structure is given as the inset.

The lattice constants of $\mathrm{C}_{2} \mathrm{~N}$ and $\mathrm{C}_{3} \mathrm{~N}$ are found to be 8.345 and $4.861 \AA$, respectively, which are in agreement with previous results. ${ }^{10,12,14,68-71}$ For $\mathrm{C}_{2} \mathrm{~N}, d_{\mathrm{C}-\mathrm{N}}=1.342 \AA$ and $d_{\mathrm{C}-\mathrm{C}}=1.429$ and $1.457 \AA$, while the bond angle of $\mathrm{C}-\mathrm{N}-\mathrm{C}$ is $117^{\circ}$, slightly deviating from $120^{\circ}$. The holey site of $\mathrm{C}_{2} \mathrm{~N}$ forms a nanopore with a diameter of $5.503 \AA$. $^{9}$ For $\mathrm{C}_{3} \mathrm{~N}$, we have $d_{\mathrm{C}-\mathrm{C}}=1.404 \AA$ and $d_{\mathrm{C}-\mathrm{N}}=1.403 \AA . \mathrm{C}_{3} \mathrm{~N}_{2}$ involves two pentagon cores surrounded by
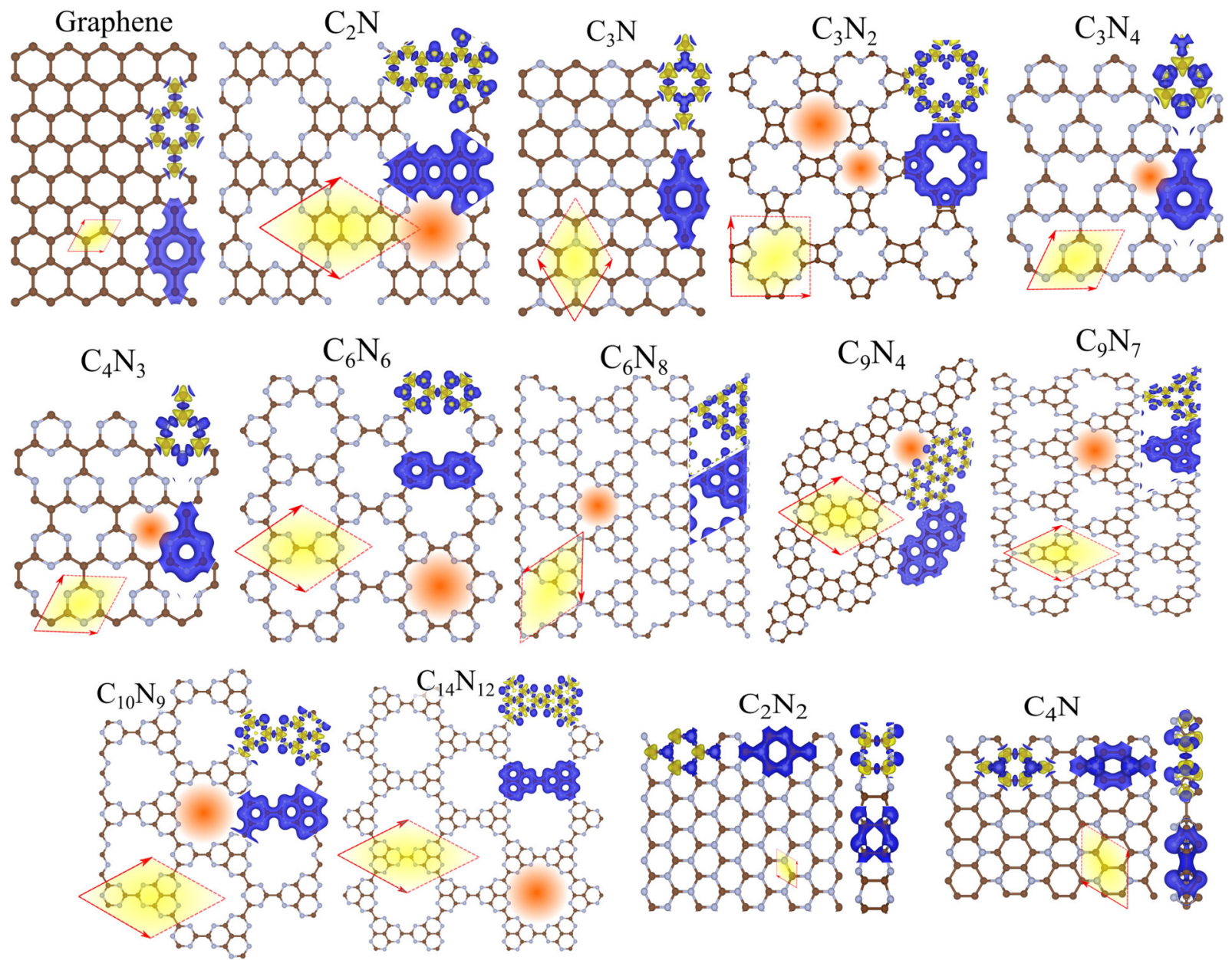

FIG. 1. Geometric structures of graphene and 2DCN nanosheets. A primitive unit cell is indicated by a red parallelogram with total and difference charge densities as shown in the same panel. The blue and yellow regions represent charge accumulation and depletion, respectively, with the brown atoms representing $\mathrm{C}$ and the blue atoms representing $\mathrm{N}$. The orange circles represent the regions of nanopores. 
$\mathrm{C}$ and $\mathrm{N}$ atoms and one core surrounded by $\mathrm{N}$ atoms and has a lattice parameter of $8.70 \AA$. The structure is completely planar, in addition we see two nanopores with diameters of 5.545 and $4.254 \AA^{72,73}$ The lattice constant of $\mathrm{C}_{3} \mathrm{~N}_{4}\left(\mathrm{C}_{4} \mathrm{~N}_{3}\right)$ is calculated to be 4.74 (4.81) $\AA$ with $d_{\mathrm{C}-\mathrm{C}}=1.323 \quad(1.427) \AA$ and $d_{\mathrm{C}-\mathrm{C}}=1.445$ (1.346) $\AA^{74}$ After structural relaxation, the calculated lattice constant for $\mathrm{C}_{6} \mathrm{~N}_{6}$ is $7.11 \AA$, consistent with previous theoretical and experimental reports. ${ }^{75-77}$ The hexagonal nanopore in $\mathrm{C}_{6} \mathrm{~N}_{6}$ has a diameter of $5.447 \AA$, which is the distance from one $\mathrm{N}$ atom to the opposite $\mathrm{N}$ atom across the nanopore with a completely planar lattice. ${ }^{30} \mathrm{C}_{6} \mathrm{~N}_{8}$ has a lattice constant of $7.14 \AA$, which is in agreement with previous studies ${ }^{27,75,78-80}$ and $d_{\mathrm{C}-\mathrm{N}}$ can have two values of 1.414 and $1.455 \AA$.

The structure of $\mathrm{C}_{9} \mathrm{~N}_{4}$ involves $18 \mathrm{C}$ and $8 \mathrm{~N}$ atoms, in its unit cell resulting in a geometry similar to $\mathrm{C}_{2} \mathrm{~N}$ and $\mathrm{C}_{3} \mathrm{~N}$ so that the unit cell of $\mathrm{C}_{9} \mathrm{~N}_{4}$ is twice that of $\mathrm{C}_{3} \mathrm{~N}$ by removing another $\mathrm{C}$ hexagonal ring, while the $\mathrm{N}$ constitutes a honeycomb structure. The lattice constant of $\mathrm{C}_{9} \mathrm{~N}_{4}$ is $9.72 \AA$ and $d_{\mathrm{C}-\mathrm{C}}\left(d_{\mathrm{C}-\mathrm{N}}\right)=1.348$ (1.407) $\AA$. The edge of $\mathrm{C}_{9} \mathrm{~N}_{4}$ nanopore is surrounded by six $\mathrm{N}$ atoms in these rings, with diameter of the nanopore of $5.588 \AA$. These results are in good agreement with previous calculations. ${ }^{81}$ The primitive unit cell lattice of $\mathrm{C}_{9} \mathrm{~N}_{7}$ constitutes one center $\mathrm{C}$ hexagon ring surrounded by three $\mathrm{CN}$ pentagons and has $8.050 \AA$ lattice constant. The $d_{\mathrm{C}-\mathrm{N}}$ in the pentagons are $1.400 \AA$ and $1.444 \AA$, which are typical bond lengths for $s p^{2}$-hybridization and noticeably smaller than $1.5 \AA$ for standard $s p^{3}$-hybridization. The diameter of the nanopore is $5.472 \AA$. The planar structure and the values of the bond lengths and bond angles imply that the chemical bonds in $\mathrm{C}_{9} \mathrm{~N}_{7}$ ought to be covalent of character. ${ }^{82}$ The lattice constant of $\mathrm{C}_{10} \mathrm{~N}_{9}$ is calculated to be $9.86 \AA$ and $d_{\mathrm{C}-\mathrm{C}}$ is $1.502 \AA$, which is longer than that around the center of the unit cell (i.e., $1.418 \AA$ ). ${ }^{83}$

$\mathrm{C}_{14} \mathrm{~N}_{12}$ has a planar 2D structure with a lattice constant of $11.77 \AA$, and the $\mathrm{C}-\mathrm{C}$ bond length is $1.435 \AA$, while the $\mathrm{C}-\mathrm{N}$ bonds are $1.365 \AA$ with the $\mathrm{C}-\mathrm{C}-\mathrm{C}$ and $\mathrm{N}-\mathrm{C}-\mathrm{N}$ angles equal to $116^{\circ}$ and $119^{\circ}$, respectively, which is consistent with the value reported in Refs. 83 and 84 . The diameter of the nanopore in $\mathrm{C}_{10} \mathrm{~N}_{9}$ and $\mathrm{C}_{14} \mathrm{~N}_{12}$ are 7.30 and $9.698 \AA$, respectively. $\mathrm{C}_{2} \mathrm{~N}_{2}$ is a bilayer structure with a lattice constant of $2.35 \AA$ and interlayer distance $d_{\mathrm{C}-\mathrm{C}}=1.443 \AA$, and layer thickness of $2.865 \AA$. The bond angle is comparable with a regular tetrahedral carbon with $s p^{3}$-hybridization of $109^{\circ}$, but $\mathrm{C}_{2} \mathrm{~N}_{2}$ shows a slight deviation from the standard tetrahedral carbon structure. The interlayer coupling is strong and is different from the weak van der Waals (vdW) coupling. By adsorbing $\mathrm{C}$ atoms on all the $\mathrm{N}$ atoms of the monolayer $\mathrm{C}_{3} \mathrm{~N}$, one obtains $\mathrm{C}_{4} \mathrm{~N}$. The lattice constant of $\mathrm{C}_{4} \mathrm{~N}$ is $4.77 \AA$ and $d_{\mathrm{C}-\mathrm{C}}\left(d_{\mathrm{C}-\mathrm{N}}\right)$ is $1.443(1.343) \AA$. The $\mathrm{C}_{4} \mathrm{~N}$ ring is not a regular hexagon since the $\mathrm{C}-\mathrm{N}-\mathrm{C}$ and $\mathrm{N}-\mathrm{C}-\mathrm{N}$ angles are equal to $114^{\circ}$ and $125^{\circ}$, respectively. These results are in good agreement with previous theoretical reports. ${ }^{85}$ This structure with nanopores can be used as a material with reactive regions inside and thereby is optimal for functionalization by adatoms or molecules.

The total and difference charge density are shown in Fig. 1, in the same panel, where the blue and yellow regions represent the charge accumulation and depletion, respectively. From the difference
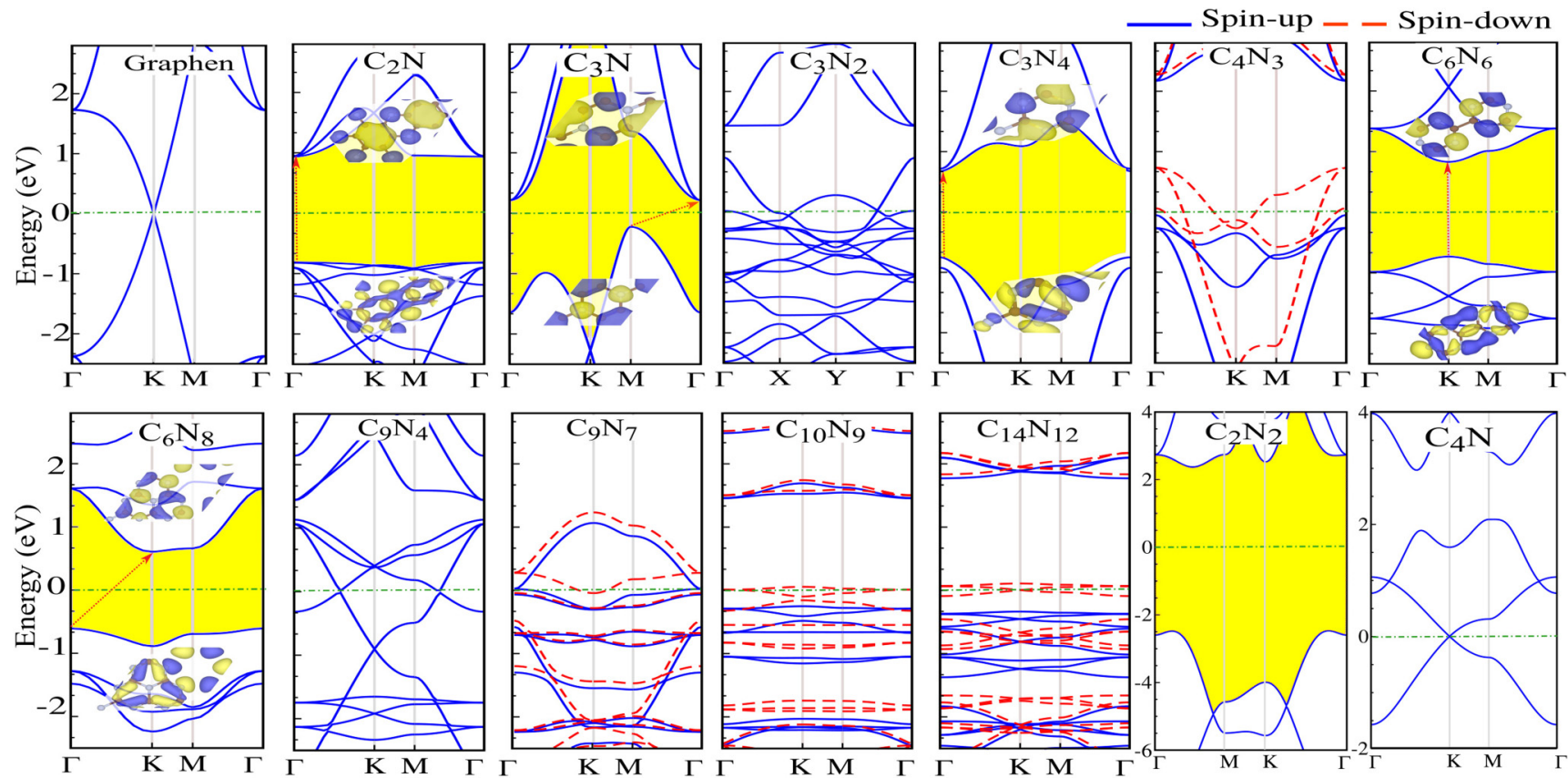

FIG. 2. Electronic band structure of graphene and $2 \mathrm{DCN}$ nanosheets. The insets are charge densities of minimum conduction band and the maximum valence band. The blue and yellow regions represent charge accumulation and depletion, respectively. The gap region between conduction and valence bands is colored yellow. The zero of energy is set to the Fermi level energy $\left(E_{F}\right)$. 
charge density, we found that the positively charged $\mathrm{C}$ atoms are surrounded by negatively charged $\mathrm{N}$ atoms. The total charge density shows a high charge density around the $\mathrm{N}$ atoms. This is in accordance with the Pauling scale electronegativity that $\mathrm{N}$ atoms have a larger electronegativity ( $\mathrm{C}$ is 2.55 and $\mathrm{N}$ is 3.04 ), and thereby a large difference of electron density. Simulated STM images of graphene and 2DCN nanosheets are shown in Fig. S3 (see the supplementary material). The inset structure represents repeating unit cells, with the brown (blue) atoms representing $\mathrm{C}(\mathrm{N})$ atom. From the predicted STM images of $2 \mathrm{DCN}$, it is easy to recognize and correlate them with the corresponding atomistic structure.

The electronic band structure of graphene and 2DCN nanosheets is shown in Fig. 2. It is well known that graphene is a semimetal with a zero gap at $E_{F}$ where the valence and conduction bands cross with linear dispersions, so-called Dirac-cones in good agreement with Refs. $86-89$. We see that $\mathrm{C}_{2} \mathrm{~N}$ is a direct semiconductor with a $1.75 \mathrm{eV}$ bandgap, and the $\mathrm{VBM}$ and $\mathrm{CBM}$ are located at the $\Gamma$ point. However, $\mathrm{C}_{3} \mathrm{~N}$ is a semiconductor with an indirect bandgap of $0.4 \mathrm{eV}$, where the VBM and CBM are located at $\Gamma$ and $\mathrm{M}$ points, respectively. Our result is in agreement with previous calculations. ${ }^{10,90-93}$ A Dirac-point which is $2.25 \mathrm{eV}$ below $E_{F}$ is shown in the band structure of $\mathrm{C}_{3} \mathrm{~N}$ (see Fig. 2). The electronic structure of $\mathrm{C}_{3} \mathrm{~N}_{2}$ exhibits a semimetal character, and we see three Dirac-points at and near $E_{F}$. There are two extra crossing points that are located along $\Gamma-\mathrm{X}$ and $\mathrm{X}-\mathrm{Y}$. This unique electronic property is different from other $2 \mathrm{DCN}$, and this result coincides well with those obtained by previous calculations. ${ }^{72,73} \mathrm{C}_{3} \mathrm{~N}_{4}$ is a direct semiconductor and has a $1.45 \mathrm{eV}$ bandgap at the $\Gamma$ point, which is in agreement with previous studies. ${ }^{21,22}$ In contrast with $\mathrm{C}_{3} \mathrm{~N}_{4}$, $\mathrm{C}_{4} \mathrm{~N}_{3}$ is a half-metal with a $0.55 \mathrm{eV}$ direct bandgap in the $\uparrow$ spin channel. In addition, the degeneracy of $\uparrow$ and $\downarrow$ spin channels is broken and shows spin-polarization at the $E_{F}$ with $1 \mu_{B}$ magnetic moment per unit cell. Our result is in agreement with previous calculations. ${ }^{24-27,94}$ The band structure indicates that $\mathrm{C}_{6} \mathrm{~N}_{6}$ is a wide bandgap semiconductor with gap values of $1.5,2.4$, and $1.35 \mathrm{eV}$ that are located at the $\mathrm{K}, \Gamma$, and $\mathrm{M}$ points, respectively (see Fig. 2). This result agrees with the previous report. ${ }^{30}$

$\mathrm{C}_{6} \mathrm{~N}_{8}$ is an indirect semiconductor with a bandgap of $1.22 \mathrm{eV}$ that agrees with Ref. 95. Similar to $\mathrm{C}_{3} \mathrm{~N}_{2}, \mathrm{C}_{9} \mathrm{~N}_{4}$ is a semimetal and we see that there are three Dirac-points at and near the $E_{F}$. At the

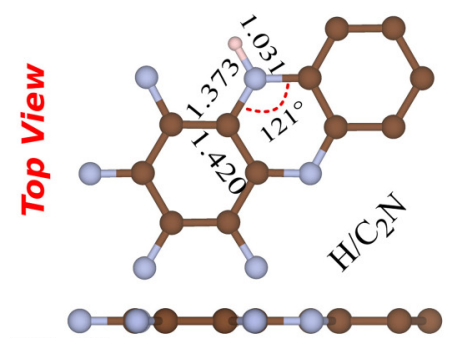

Side View
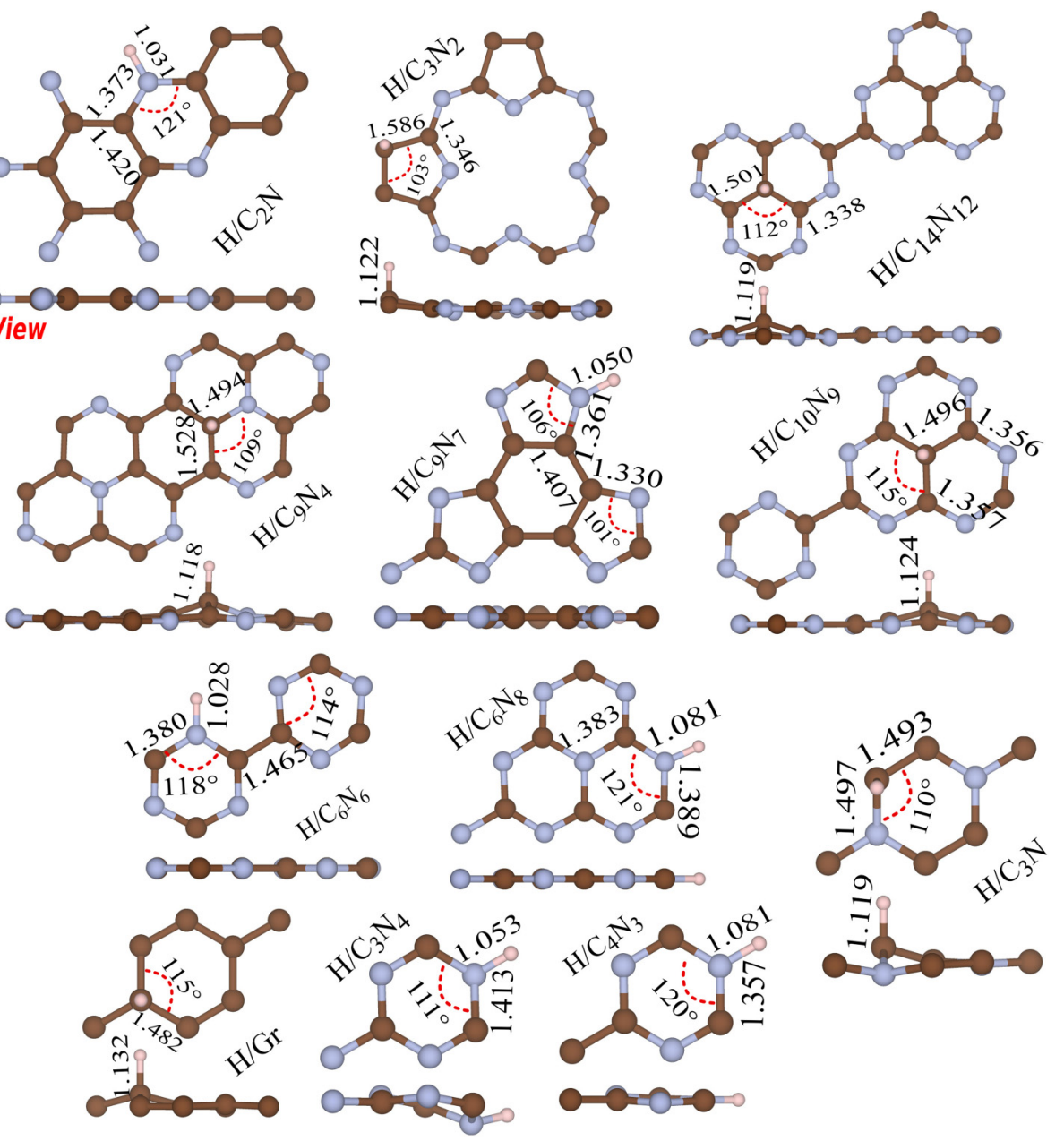

FIG. 3. Optimized structures of $\mathrm{H}$ adsorbed on graphene and $2 \mathrm{DCN}$ nanosheets with their structural properties. Top and side views are presented. 

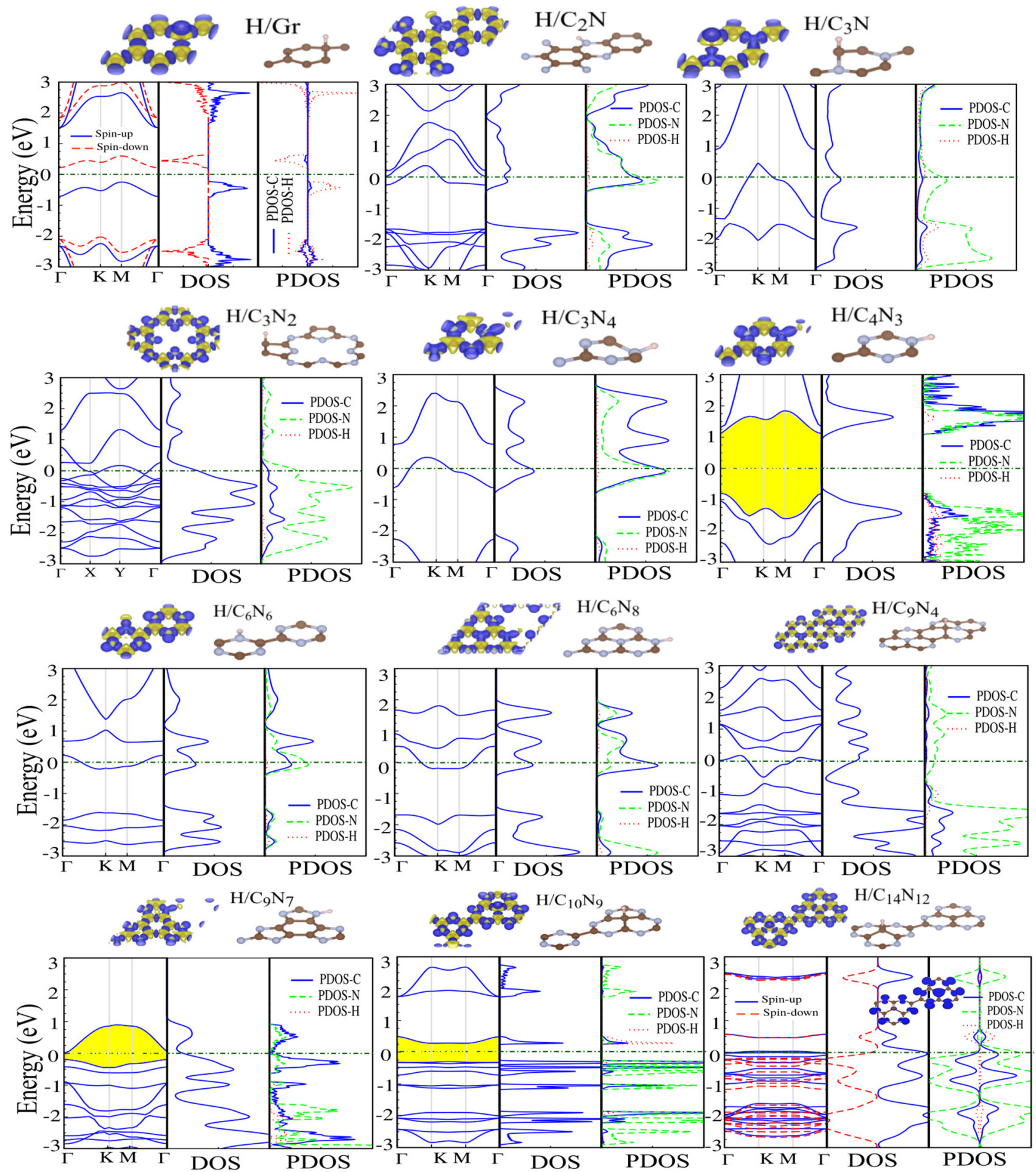

FIG. 4. Electronic band structure with the corresponding DOS of $\mathrm{H}$-adsorbed graphene and 2DCN nanosheets. The difference charge density and optimized structures are shown in the same panel. The blue and yellow regions represent the charge accumulation and depletion, respectively. The difference spin density with magnetic moment is shown as the inset. The blue and yellow regions represent the $\uparrow$ and $\downarrow$ spin states, respectively. The zero of energy is set at $E_{F}$ indicated by green dasheddotted lines. The gap region between conduction and valence bands is colored yellow. 
$\mathrm{K}$ point, there is one extra crossing point that is located $\sim 1 \mathrm{eV}$ below $E_{F}$ and a narrow bandgap of $40 \mathrm{meV}$ is seen near $E_{F}$, which agrees well with those obtained by a previous study. ${ }^{81}$ For $\mathrm{C}_{9} \mathrm{~N}_{7}$, the energy band splits into $\uparrow$ and $\downarrow$ spin channels resulting in a ferromagnetic-metal. It is interesting to see that $\mathrm{C}_{9} \mathrm{~N}_{7}$ has a spinpolarized ground state with $0.8 \mu_{B}$ magnetic moment per unit cell. Our result agrees well with Ref. 82. The band structures of $\mathrm{C}_{10} \mathrm{~N}_{9}$ and $\mathrm{C}_{14} \mathrm{~N}_{12}$ are shown in Fig. 2. We found that a remarkable spin-splitting occurs in the $\uparrow$ and $\downarrow$ spin channels near to $E_{F}$. The $\mathrm{CB}$ and $\mathrm{VB}$ of the $\downarrow$ spin channel meet in a single point at $E_{F}$, whereas bandgaps of approximately $1.7 \mathrm{eV}\left(\mathrm{C}_{10} \mathrm{~N}_{9}\right)$ and $2.1 \mathrm{eV}$ $\left(\mathrm{C}_{14} \mathrm{~N}_{12}\right)$ are noted in the $\uparrow$ spin channel, exhibiting clear features of a spin-glass semiconductor. $\mathrm{C}_{10} \mathrm{~N}_{9}$ and $\mathrm{C}_{14} \mathrm{~N}_{12}$ have 1 and $2 \mu_{B}$ magnetic moment in their ground states, respectively. Interestingly, the charge carriers (electrons and holes) near $E_{F}$ behave differently around the meeting point. For $\mathrm{C}_{10} \mathrm{~N}_{9}$, the $\mathrm{VB}$ and $\mathrm{CB}$ in the $\downarrow$ spin channel meet at the $\Gamma$ point with parabolic energy-momentum dispersion relations, while for $\mathrm{C}_{14} \mathrm{~N}_{12}$ two bands meet at the $\mathrm{K}$ point and have a linear energy dispersion characterized by the so-called Dirac-cones. The Dirac-cones in $\mathrm{C}_{14} \mathrm{~N}_{12}$ are spin-polarized and energy bands split into $\uparrow$ and $\downarrow$ spin channels, which is different from graphene, $\mathrm{C}_{3} \mathrm{~N}_{2}, \mathrm{C}_{9} \mathrm{~N}_{4}$, and other Dirac materials. For $\mathrm{C}_{4} \mathrm{~N}$, we see that the VBM and CBM energy bands touch each other at $E_{F}$ and a Dirac-point is formed at $E_{F}$, implying a semimetallic character, like graphene. While $\mathrm{C}_{2} \mathrm{~N}_{2}$ is an insulator with a $5 \mathrm{eV}$ bandgap and interestingly we see two Dirac-points that are located $\sim 5 \mathrm{eV}$ below $E_{F}$. DOS and PDOS of pristine graphene and 2DCN nanosheets are shown in Fig. $\mathrm{S} 4$ (see the supplementary material). Direct semiconducting behavior of $\mathrm{C}_{2} \mathrm{~N}, \mathrm{C}_{3} \mathrm{~N}, \mathrm{C}_{3} \mathrm{~N}_{4}, \mathrm{C}_{6} \mathrm{~N}_{6}$, and
$\mathrm{C}_{6} \mathrm{~N}_{8}$ can be quite useful for nanoelectronic and optoelectronic applications. Note that the half-metallicity of $\mathrm{C}_{4} \mathrm{~N}_{3}$ and the ferromagnetic behavior of $\mathrm{C}_{9} \mathrm{~N}_{7}$ can be quite important for spintronic applications. The unusual semimetallic electronic property of $\mathrm{C}_{4} \mathrm{~N}$, $\mathrm{C}_{3} \mathrm{~N}_{2}$, and $\mathrm{C}_{9} \mathrm{~N}_{4}$ shows Dirac-points at $E_{F}$, which can be important for various applications. The spin-gapless semiconductors $\mathrm{C}_{10} \mathrm{~N}_{9}$ and $\mathrm{C}_{14} \mathrm{~N}_{12}$ are expected to open up many prospects for practical applications, such as spin photodiodes, spin detectors, and electromagnetic radiation generators over a wide range of wavelengths based on spin photoconductivity.

\section{ADSORPTION OF H ATOM}

Additionally, the adsorption of adatoms will affect the structural, electronic, and magnetic properties of pristine $2 \mathrm{DCN}$ nanosheets. The calculations are performed using a $2 \times 2$ supercell of $\mathrm{C}_{3} \mathrm{~N}$, with fully structural optimizations, where all atoms are relaxed in all directions. The optimized atomic structures of a $2 \times 2$ supercell of graphene and 2DCN nanosheets are shown in Fig. S5 (a) of the supplementary material. Also, the variations of structural parameters including lattice constant, atomic bond lengths, and nanopore diameter, are shown in Figs. S5(b)-S5(d) of the supplementary material. After structural optimization of the $2 \times 2$ supercell of the $2 \mathrm{DCN}$, we investigate the electronic and magnetic properties. The spin-polarized electronic band structure of the $2 \times 2$ supercell of graphene and different $2 \mathrm{DCN}$ is shown in Fig. S6 of the supplementary material.

Here, we consider the functionalization by hydrogen. The minimum energy or most stable sites of the $\mathrm{H}$ adatom on the
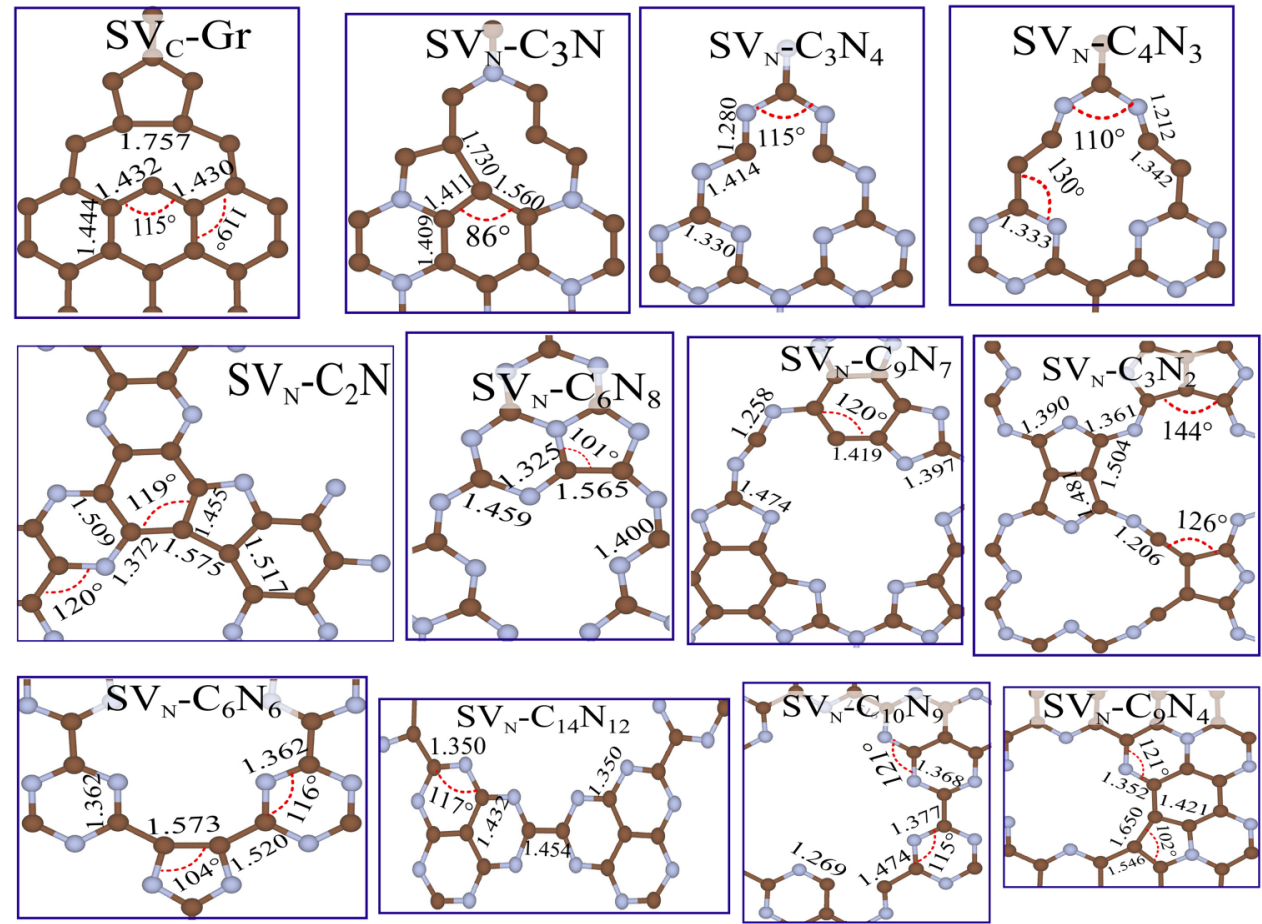

FIG. 5. Optimized structures of the $\mathrm{N}$-vacant site of different $2 \mathrm{DCN}$ nanosheets and of the C-vacant site in graphene. Structural parameters including atomic bond length and bond angles are indicated. $\mathrm{C}, \mathrm{N}$, and $\mathrm{H}$ atoms are shown by brown, blue, and white colors, respectively. 
surface of $2 \mathrm{DCN}$ are obtained by placing $\mathrm{H}$ on various preferable adsorption sites. With fully structure optimization, where all atoms are relaxed in all directions, we determine the most stable site as the minimum energy configuration among the different sites. In the following, when a $\mathrm{H}$ atom is adsorbed on a $2 \mathrm{DCN}$ nanosheet, we will label it as $\mathrm{H} / 2 \mathrm{DCN}$. The top and side views of optimized structures of $\mathrm{H}$ adsorbed on graphene and 2DCN nanosheets are shown in Fig. 3. The $\mathrm{H}$ atom is located right above a $\mathrm{C}$ atom of the $\mathrm{C}_{3} \mathrm{~N}$ and $\mathrm{C}_{3} \mathrm{~N}_{2}$, forming a single covalent bond and a local distortion can occur in the structure and the $\mathrm{C}$ atoms directly below $\mathrm{H}$ undergoes a notable shifting toward the opposite direction, resulting in a buckling of about $0.5 \AA$. After relaxation, the $\mathrm{C}-\mathrm{H}$ bond length is $1.12 \AA$, while the $\mathrm{C}-\mathrm{C}$ and $\mathrm{C}-\mathrm{N}$ bonds are elongated to 1.5 and $1.58 \AA$, respectively, which compares to the $\mathrm{C}-\mathrm{C}$ bond length $1.42 \AA$ in pristine nanosheets, while bond angles between
$\mathrm{C}-\mathrm{C}-\mathrm{C}$ and $\mathrm{C}-\mathrm{N}-\mathrm{C}$ are in the range of $110^{\circ}$ and $103^{\circ}$, respectively, and show $s p^{3}$-hybridization character. For the $\mathrm{C}_{3} \mathrm{~N}_{4}, \mathrm{C}_{4} \mathrm{~N}_{3}$, $\mathrm{C}_{6} \mathrm{~N}_{6}$, and $\mathrm{C}_{6} \mathrm{~N}_{8}$ nanosheets, the $\mathrm{H}$ atom is bonded to the $\mathrm{N}$ atom and forms a covalent bond which results in elongated $\mathrm{N}-\mathrm{C}$ bonds with lengths $1.35-141 \AA$, while the $\mathrm{N}-\mathrm{H}$ bond lengths are very short in the range of $1.02-1.08 \AA$. For $\mathrm{C}_{9} \mathrm{~N}_{4}, \mathrm{C}_{10} \mathrm{~N}_{9}$, and $\mathrm{C}_{14} \mathrm{~N}_{12}$ nanosheets, the $\mathrm{H}$ atom is located right above a $\mathrm{C}$ atom and a local deformation occurs around the $\mathrm{H}$ atom, and after relaxation, different $\mathrm{C}-\mathrm{H}$ bond lengths are determined to be about 1.11$1.12 \AA$. We see that the $\mathrm{C}$ atoms directly below $\mathrm{H}$ move in the opposite direction, with $0.5 \AA$ buckling of the plane.

The electronic band structure with corresponding DOS of $\mathrm{H}$ adsorbed graphene and 2DCN nanosheets is shown in Fig. 4. The difference charge density and optimized structures are shown in the same panel. For the $\mathrm{H} / \mathrm{Gr}$, there is a band spin-splitting around $E_{F}$
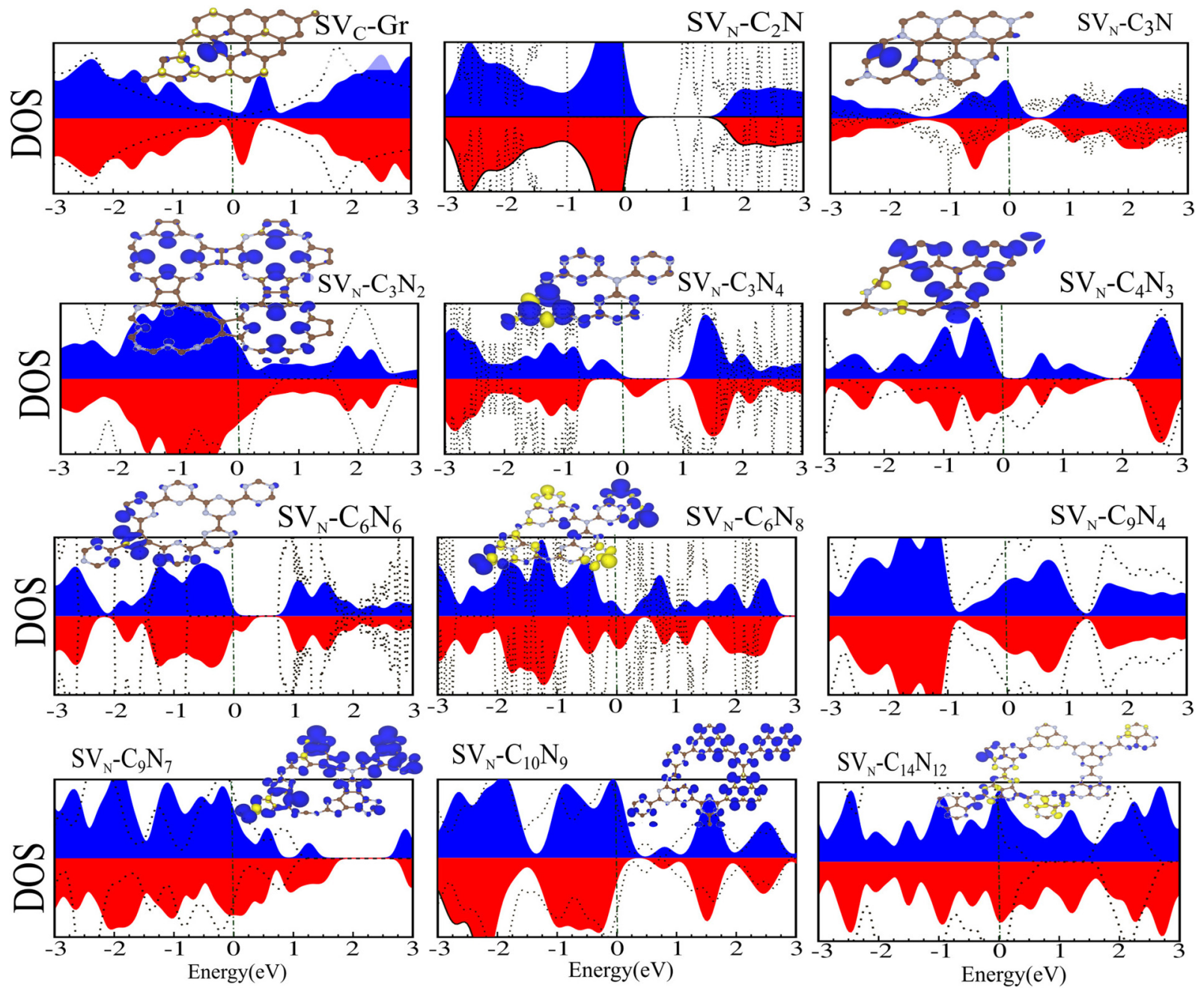

FIG. 6. Spin resolved DOS of the N-vacant site of different 2DCN nanosheets and for the C-vacant site of graphene. The difference spin density are shown as the insets. The blue and yellow regions represent the $\uparrow$ and $\downarrow$ spin states, respectively. The zero of energy is at $E_{F}$ indicated by the green dashed-dotted vertical lines. 


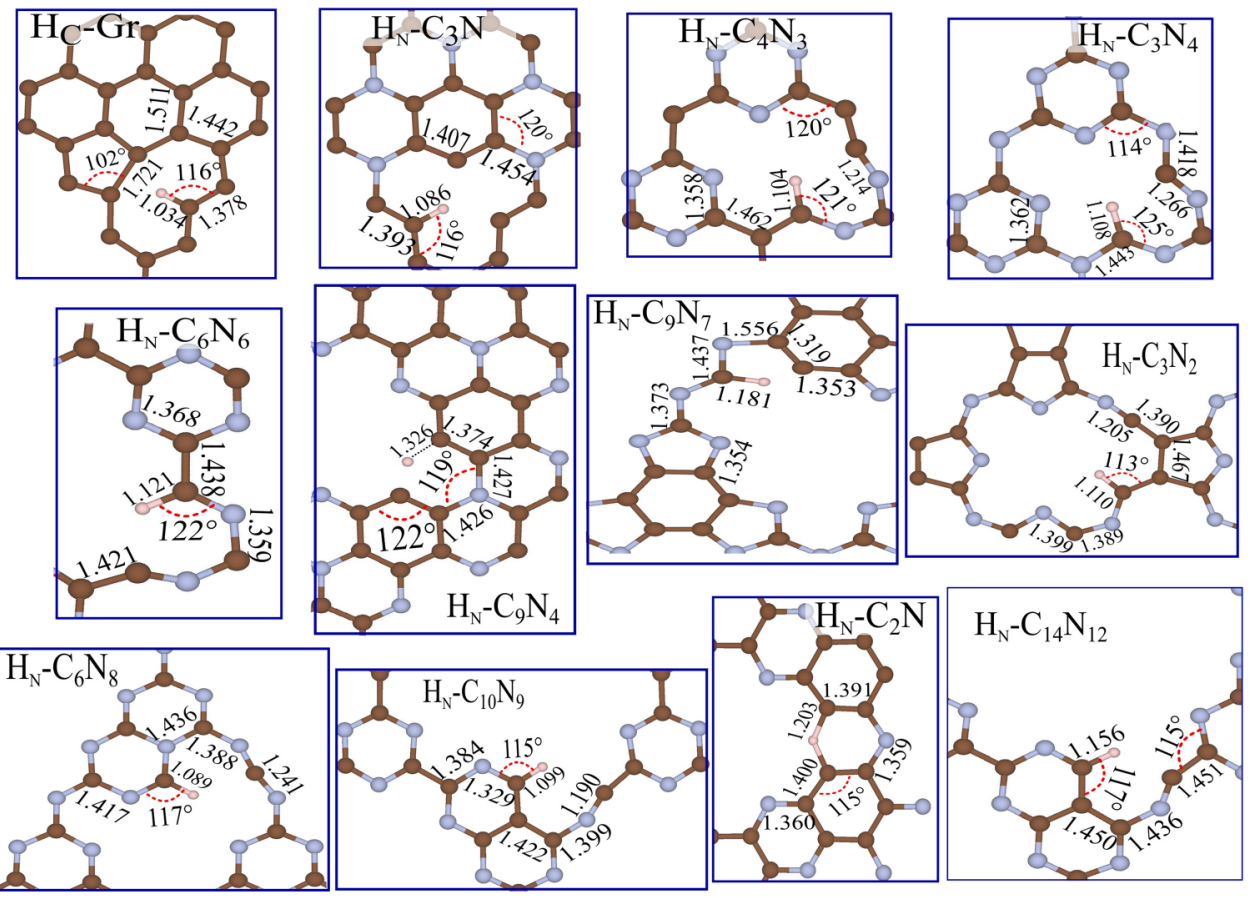

FIG. 7. Top view of optimized structures of $\mathrm{H}$-substituted in the $\mathrm{N}$-vacant site. The corresponding structural parameters including atomic bond length and bond angles are indicated. $\mathrm{C}, \mathrm{N}$, and $\mathrm{H}$ atoms are shown by brown, blue, and white colors, respectively. into $\uparrow$ and $\downarrow$ spin channels. Thus, the system becomes a dilutemagnetic semiconductor with $1 \mu_{B}$ magnetic moment. The Dirac-point disappears in $\mathrm{H} / \mathrm{Gr}$ due to the strong disturbance of the $p_{z}$ states caused by the adsorption of $\mathrm{H}$ atom. ${ }^{96,97}$ The electronic structure of adsorbed $\mathrm{H}$ on $\mathrm{C}_{2} \mathrm{~N}, \mathrm{C}_{3} \mathrm{~N}$, and $\mathrm{C}_{3} \mathrm{~N}_{2}$ is strongly modified. The energy bands below and above $E_{F}$ are mainly originating from the $\mathrm{H}$ orbital states and appear as localized impurity states. $\mathrm{H} / \mathrm{C}_{2} \mathrm{~N}, \mathrm{H} / \mathrm{C}_{3} \mathrm{~N}$, and $\mathrm{H} / \mathrm{C}_{3} \mathrm{~N}_{2}$ are metals. From the PDOS of $\mathrm{H} / \mathrm{C}_{2} \mathrm{~N}$, we found that the electron states near $E_{F}$ are mainly built up of $\mathrm{C} / \mathrm{N}-\mathrm{p}$ orbitals, while in $\mathrm{H} / \mathrm{C}_{3} \mathrm{~N}$ and $\mathrm{H} / \mathrm{C}_{3} \mathrm{~N}_{2}$, they are due to the hybridization of $\mathrm{C}-\mathrm{p}$ and $\mathrm{N}$-p orbitals of the nearest atoms. The DOS of $\uparrow$ and $\downarrow$ spin states completely compensate each other and, therefore, the materials are nonmagnetic. The interaction of $\mathrm{H}$ atoms with $\mathrm{C}_{3} \mathrm{~N}_{4}, \mathrm{C}_{6} \mathrm{~N}_{6}$, and $\mathrm{C}_{6} \mathrm{~N}_{8}$ eliminates the semiconducting behavior of the pristine system and become metals. $\mathrm{C}_{4} \mathrm{~N}_{3}$ is a halfmetal with $1 \mu_{B}$ magnetic moment, while $\mathrm{H} / \mathrm{C}_{4} \mathrm{~N}_{3}$ becomes a direct semiconductor with a $2.0 \mathrm{eV}$ bandgap. Based on the calculated PDOS, both the CBM and VBM receive contributions mainly from the hybridization of the C/N-p orbitals. $\mathrm{H} / \mathrm{C}_{9} \mathrm{~N}_{4}$ becomes a metal, and the Dirac-point vanishes due to $\mathrm{H}$ adsorption. $\mathrm{C}_{9} \mathrm{~N}_{7}$ becomes a ferromagnetic-metal and has $1 \mu_{B}$ magnetic moment, while $\mathrm{H} / \mathrm{C}_{4} \mathrm{~N}_{3}$ is an indirect semiconductor with a $0.2 \mathrm{eV}$ bandgap and both $\uparrow$ and $\downarrow$ spin bands overlap, with no net spin polarization. The interaction of $\mathrm{H}$ with $\mathrm{C}_{10} \mathrm{~N}_{9}$ eliminates the spin-glass semiconducting character and turns it into a direct semiconductor with a $0.6 \mathrm{eV}$ bandgap. Interestingly, the $\uparrow$ and $\downarrow$ spin channels for $\mathrm{H} / \mathrm{C}_{14} \mathrm{~N}_{12}$ exhibit half-metal behaviors and induce $1 \mu_{B}$ magnetic moment in the ground state. As can be seen from DOS and PDOS, for $\mathrm{H} / \mathrm{C}_{9} \mathrm{~N}_{4}$, the electron states near $E_{F}$ are mainly governed by the $\mathrm{N}$-p orbitals, while for $\mathrm{H} / \mathrm{C}_{14} \mathrm{~N}_{12}$, the VBM and CBM are due to the hybridization of C-p and N-p orbitals. In $\mathrm{H} / \mathrm{C}_{9} \mathrm{~N}_{4}$, the VBM and CBM are due to the hybridization of $\mathrm{C} / \mathrm{N}-\mathrm{p}$ and $\mathrm{H}$-s with $\mathrm{N}-\mathrm{p}$ orbitals, respectively. To illustrate the bond character more in detail, the difference charge density is shown as the insets in Fig. 4. We note there is charge accumulation in the region between $\mathrm{H}$ and the neighboring $\mathrm{C}$ and $\mathrm{N}$ atoms, resulting in a strong covalent bond of the $\mathrm{H}-\mathrm{C}$ and $\mathrm{H}-\mathrm{N}$ bonds. For clarity of the spin arrangement on each atom and to further elucidate the origin of magnetism, difference spin density is shown as the insets in Fig. 4.

\section{N-VACANCY}

Here, we will study the effect of $\mathrm{N}$-vacancy defects. We remove one $\mathrm{N}$ atom at every hexagonal and in this way produce a single vacancy of $\mathrm{N}$ atom $\left(S V_{N}\right)$. The defective structures are fully relaxed and the total energies and band structures are calculated. The top and side views of optimized atomic structures as well as their bond lengths and bond angles of the $\mathrm{N}$-vacant site of various $2 \mathrm{DCN}$, are shown in Fig. 5. The $\mathrm{C}$ and $\mathrm{N}$ atoms around the $\mathrm{N}$-vacant site in $\mathrm{C}_{2} \mathrm{~N}, \mathrm{C}_{3} \mathrm{~N}, \mathrm{C}_{3} \mathrm{~N}_{2}, \mathrm{C}_{6} \mathrm{~N}_{6}, \mathrm{C}_{9} \mathrm{~N}_{4}$, and $\mathrm{C}_{14} \mathrm{~N}_{12}$ undergo a Jahn-Teller distortion, ${ }^{98}$ and $\mathrm{C}$ atoms close to the vacancy site move toward each other to form $\mathrm{C}-\mathrm{C}$ bonds. For these structures, Jahn-Teller distortion creates a five-membered ring via an elongated bond between two of the $\mathrm{C}$ atoms nearest to the vacancy. We found for the $\mathrm{C}-\mathrm{C}$ and $\mathrm{N}-\mathrm{C}$ bond lengths, respectively, 1.50 and $1.75 \AA$ (see Fig. 5). For some of the other $2 \mathrm{DCN}$ after relaxation of the structure, the structural distortion that stems from the $\mathrm{N}$ vacancy cannot be compensated by the local reconstruction of neighboring $\mathrm{C}$ atoms. No covalent bond at the $\mathrm{N}$-vacant site is found but the $\mathrm{C}$ and $\mathrm{N}$ bond lengths around the 
$\mathrm{N}$-vacant site are modified. All $2 \mathrm{DCN}$ stay completely planar. The band structure of the $\mathrm{N}$-vacant site of $2 \mathrm{DCN}$ nanosheets is shown in Fig. S7 of the supplementary material. Our result shows that graphene with a C-vacancy, induce defect states around $E_{F}$, resulting in a half-metallic behavior and inducing a $1 \mu_{B}$ magnetic moment. We can see that $\mathrm{C}_{3} \mathrm{~N}, \mathrm{C}_{3} \mathrm{~N}_{2}, \mathrm{C}_{9} \mathrm{~N}_{7}$, and $\mathrm{C}_{14} \mathrm{~N}_{12}$ with a $\mathrm{N}$-vacancy are ferromagnetic-metal. $\mathrm{C}_{2} \mathrm{~N}$ and $\mathrm{C}_{9} \mathrm{~N}_{4}$ with a $\mathrm{N}$-vacancy, defect states appear around $E_{F}$ and induce metallic properties. With a

(a)
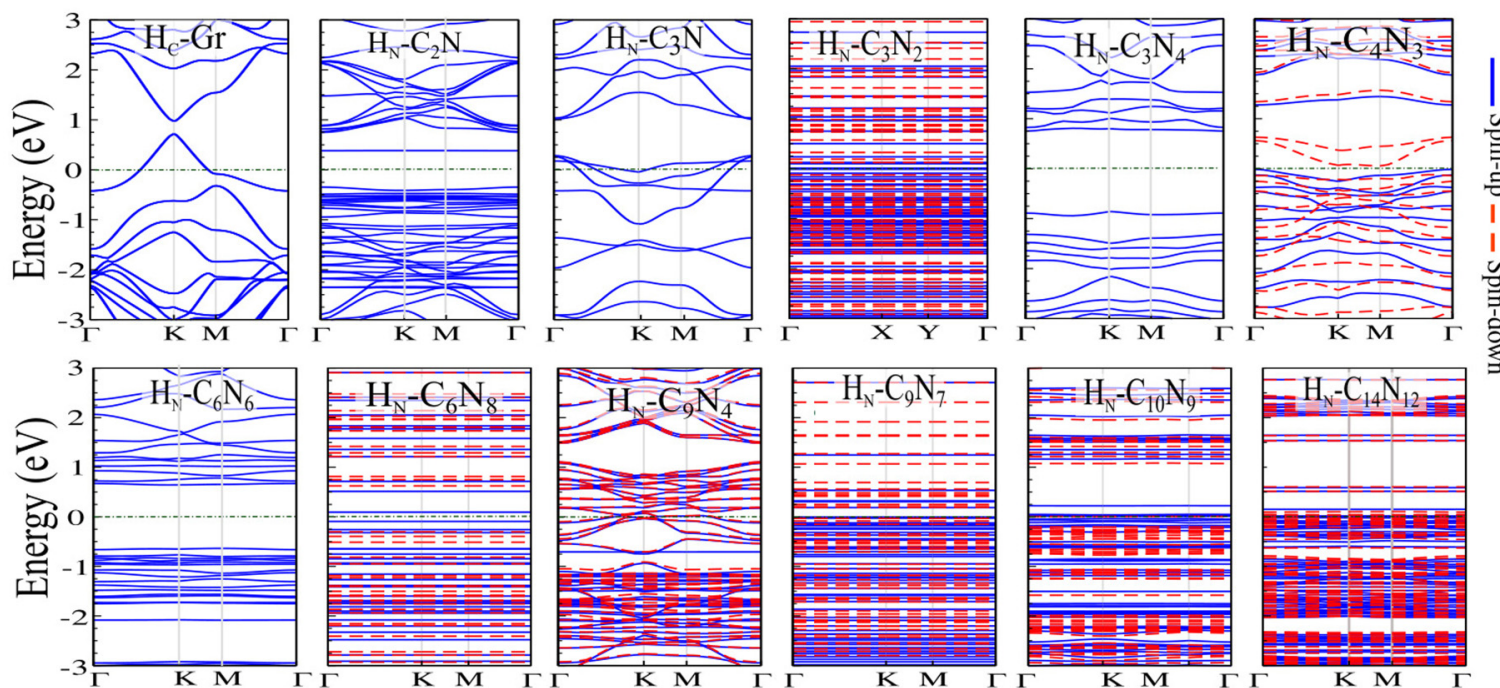

(b)
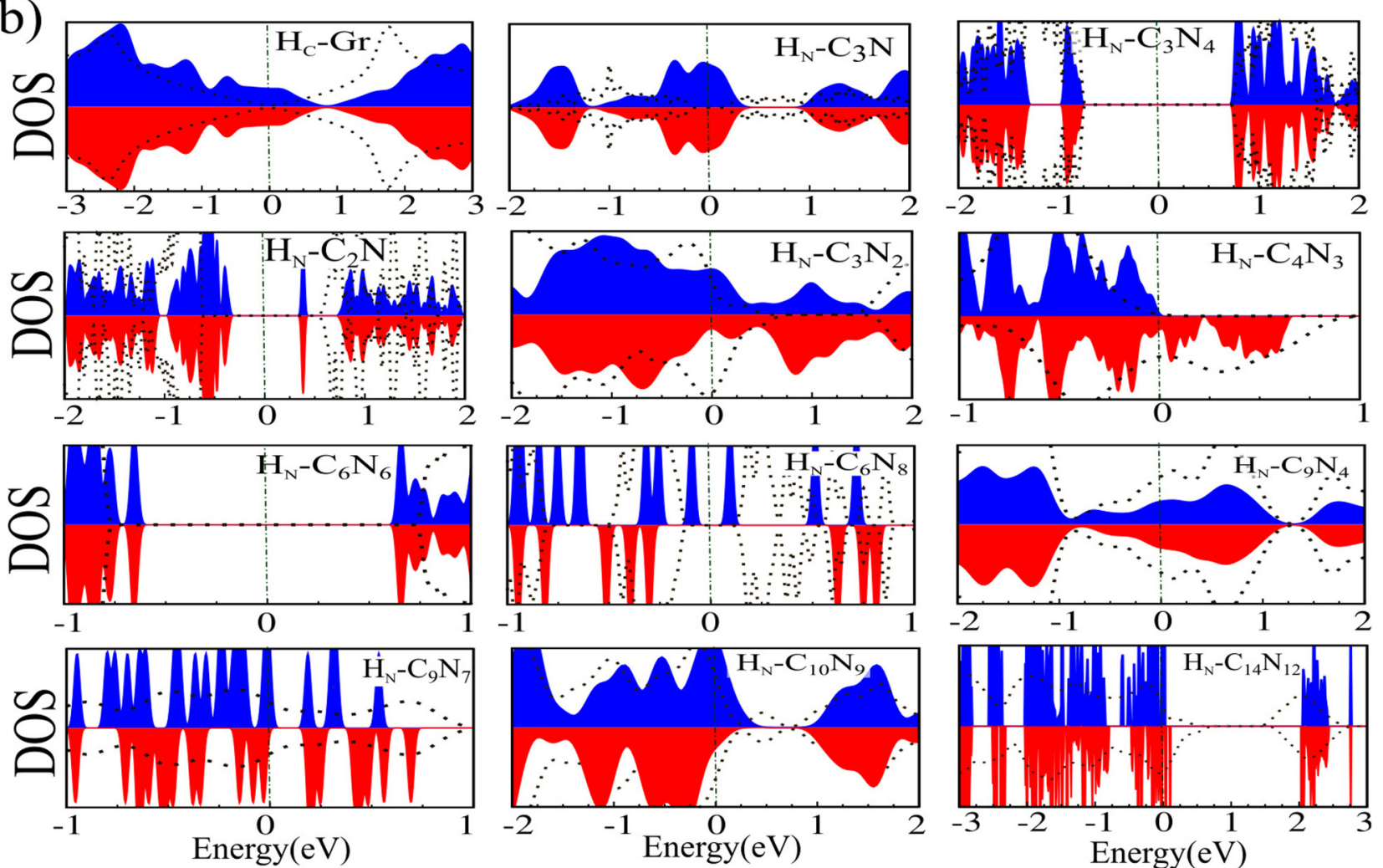

FIG. 8. (a) Electronic structure and (b) DOS of $\mathrm{H}$-substituted in the $\mathrm{N}$-vacant site. The zero of energy is set at the $E_{F}$ indicated by green dashed-dotted lines. 

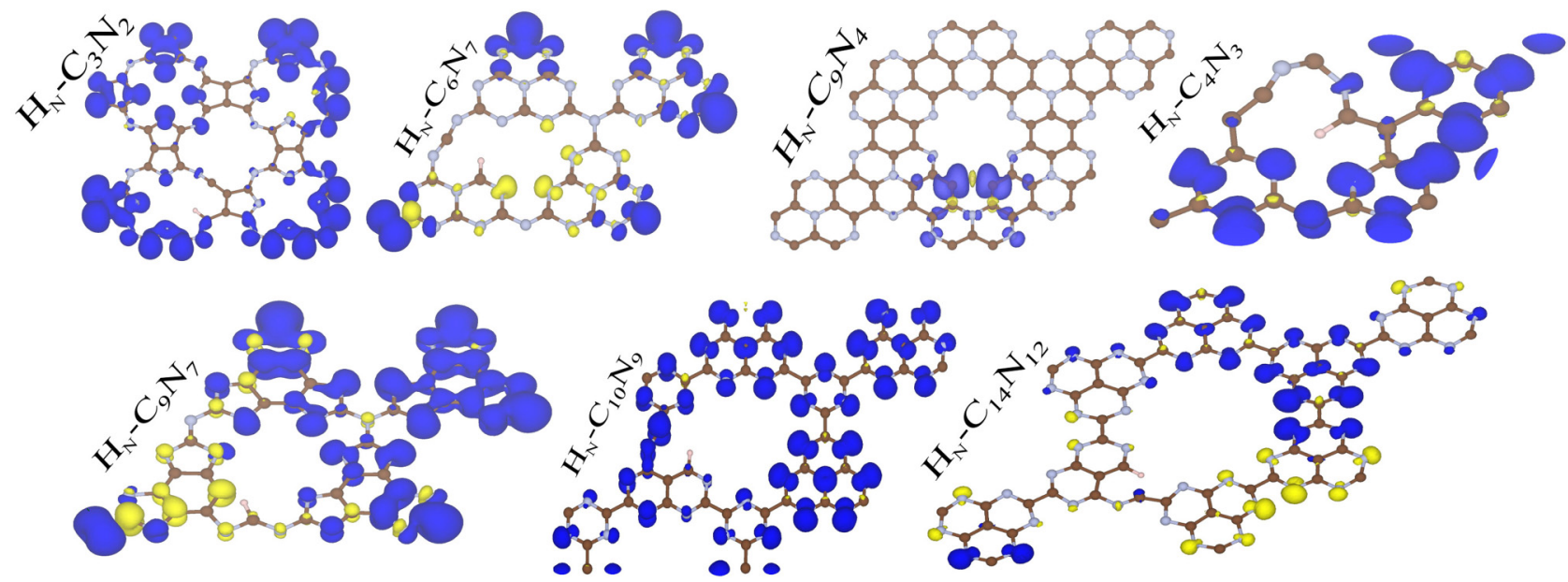

FIG. 9. Difference spin density of H-substituted in the N-vacant site of 2DCN nanosheets. The blue and yellow regions represent the $\uparrow$ and $\downarrow$ spin states, respectively.

$\mathrm{N}$-vacancy, $\mathrm{C}_{4} \mathrm{~N}_{3}$ becomes a spin-glass semiconductor, while $\mathrm{C}_{3} \mathrm{~N}_{4}$, $\mathrm{C}_{6} \mathrm{~N}_{6}$, and $\mathrm{C}_{6} \mathrm{~N}_{8}, \mathrm{C}_{10} \mathrm{~N}_{9}$ are dilute-magnetic semiconductors (see Fig. 6). The magnetic moments of dilute-magnetic semiconductor and ferromagnetic-metal structures with the $\mathrm{N}$-vacancy are in the range of $0.3\left(\mathrm{C}_{3} \mathrm{~N}\right)-7.5\left(\mathrm{C}_{9} \mathrm{~N}_{7}\right) \mu_{B}$. The spin resolved DOS of the
$\mathrm{N}$-vacant site of different $2 \mathrm{DCN}$ nanosheets and for the C-vacant site of graphene is shown in Fig. 6. The difference spin density is shown as the insets. It is also seen from the DOS that the density of $\mathrm{N}$-vacant site is very high and the state at $E_{F}$ of a $\mathrm{N}$-vacancy belongs to the $\mathrm{C} / \mathrm{N}-\mathrm{p}$ orbital around the missing $\mathrm{N}$ atom. The
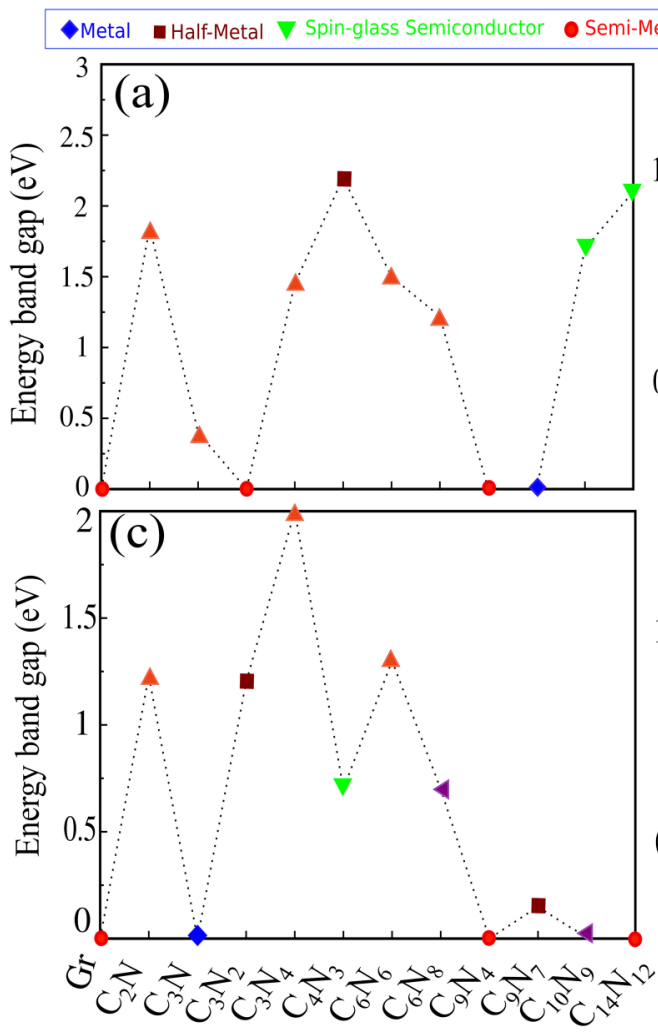
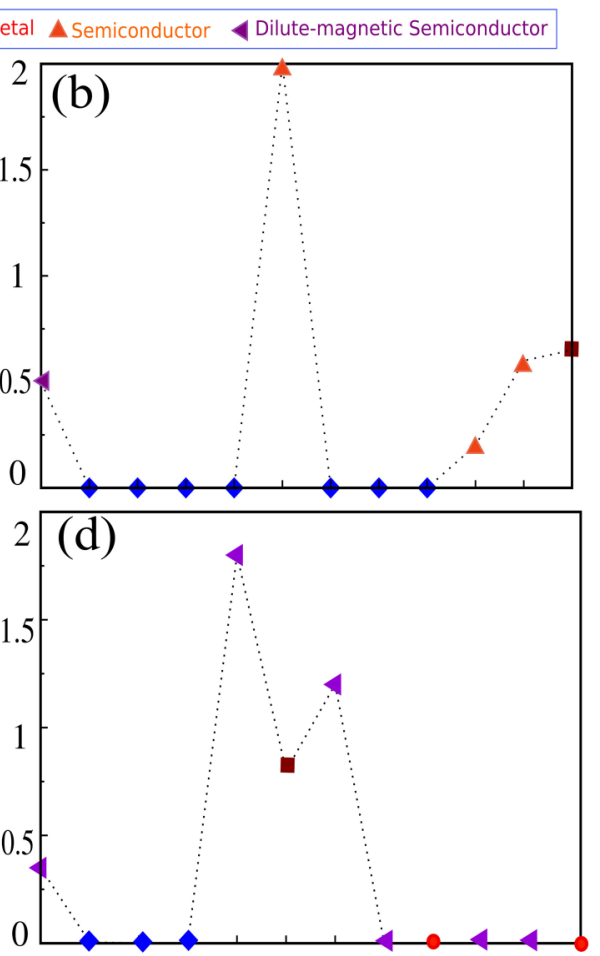

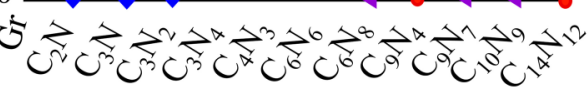

FIG. 10. Variation of bandgap of (a) 2DCN, (b) H-adsorbed 2DCN, (c) $\mathrm{H}$-substituted 2DCN, and (d) N-vacancy $2 \mathrm{DCN}$. 
energy band of $2 \mathrm{DCN}$ is strongly disturbed by the N-vacant site, thus the bonding between atoms should be a covalent bond. To illustrate the bond character more clearly, the differential charge density for 2DCN with th $\mathrm{N}$-vacant site is presented in Fig. S8 of the supplementary material. There is a charge accumulation in the region around $S V_{N}$ that leads to a strong covalent bond character of the $\mathrm{C}$ and $\mathrm{N}$ bonds. Our results show that the $\mathrm{N}$-vacant site in 2DCN can modify the electronic structure and tune the bandgap and magnetism in these structures. Our result shows that graphene with a C-vacancy induces defect states around $E_{F}$, resulting in a half-metallic behavior and inducing a $1 \mu_{B}$ magnetic moment. We see that $\mathrm{C}_{3} \mathrm{~N}, \mathrm{C}_{3} \mathrm{~N}_{2}, \mathrm{C}_{9} \mathrm{~N}_{7}$, and $\mathrm{C}_{14} \mathrm{~N}_{12}$ with a $\mathrm{N}$-vacancy are ferromagnetic-metal. $\mathrm{C}_{2} \mathrm{~N}$ and $\mathrm{C}_{9} \mathrm{~N}_{4}$ with a $\mathrm{N}$-vacancy defect states appear around $E_{F}$ and induce metallic properties.

\section{SUBSTITUTION OF N BY H}

In the experimental synthesis of nanomaterials, the $\mathrm{N}$-vacant sites are more likely to be substituted by an $\mathrm{H}$ atom. Therefore, we consider $\mathrm{N}$ substitution by $\mathrm{H}$ which we label as $H_{N}-\mathrm{C} 2 \mathrm{DCN}$. Calculations are performed using a $2 \times 2$ supercell of $2 \mathrm{DCN}$, with fully structure optimizations, where all atoms are relaxed in all directions. The top view of optimized structures of $\mathrm{H}$-substituted in the $\mathrm{N}$-vacant site is shown in Fig. 7. The corresponding, structural parameters including atomic bond length and bond angles are indicated. $\mathrm{C}, \mathrm{N}$, and $\mathrm{H}$ atoms are shown by brown, blue, and white colors, respectively. The $H_{N}-2 \mathrm{DCN}$ shows a local distortion that is minute and the hexagonal crystal symmetry of $2 \mathrm{DCN}$ is not strongly modified. The $\mathrm{H}$ atom interacts through $s p^{2}$-hybridization and forms one $\sigma$ bond with the nearest $\mathrm{C}$ atom of the different $2 \mathrm{DCN}$. The $\mathrm{C}-\mathrm{H}$ bond lengths of $2 \mathrm{DCN}$ are in the range of $\sim 1.08-1.12 \AA$, which are small, indicating a strong interaction between the $\mathrm{H}$ and $\mathrm{C}$ atoms. We note that the bond length of $\mathrm{C}-\mathrm{C}$ and $\mathrm{N}-\mathrm{C}$ atoms and bond angles around $H_{N}$ are modified. $H_{N}$ in $\mathrm{C}_{2} \mathrm{~N}, \mathrm{C}_{3} \mathrm{~N}_{4}, \mathrm{C}_{4} \mathrm{~N}_{3}$, and $\mathrm{C}_{6} \mathrm{~N}_{6}$ changes the bond lengths and bond angle, and corrugation of the planar structures is found. For the other 2DCN nanosheets with $H_{N}$, there is only a minute effect on the planar structure. The electronic structure and DOS of $\mathrm{H}$-substituted in the $\mathrm{N}$-vacant site are shown in Figs. 8(a) and 8(b). Defect states appear near $E_{F}$, induce metallic character, and the system turns to a nonmagnetic metal. $H_{N} \mathrm{C}_{4} \mathrm{~N}_{3}$ becomes a spinglass semiconductor and induce $2 \mu_{B}$ magnetic moment. While $\mathrm{C}_{2} \mathrm{~N}, \mathrm{C}_{3} \mathrm{~N}_{4}, \mathrm{C}_{6} \mathrm{~N}_{6}$ with $H_{N}$ are semiconductors. Difference spin density of the $\mathrm{H}$-substituted $\mathrm{N}$-vacant site of $2 \mathrm{DCN}$ nanosheets is shown in Fig. 9. The blue and yellow regions represent the $\uparrow$ and $\downarrow$ spin states, respectively. The differential charge density is presented in Fig. S9 of the supplementary material. The blue and yellow regions represent charge accumulation and depletion, respectively. We can see an obvious charge accumulation in the region around $H_{N}$ resulting in a strong covalent bond of the $\mathrm{C}$ and $\mathrm{N}$ bonds. The variations of the bandgap and the magnetic moment of $2 \mathrm{DCN}$, $\mathrm{H}$-adsorbed 2DCN, H-substituted 2DCN and N-vacancy 2DCN

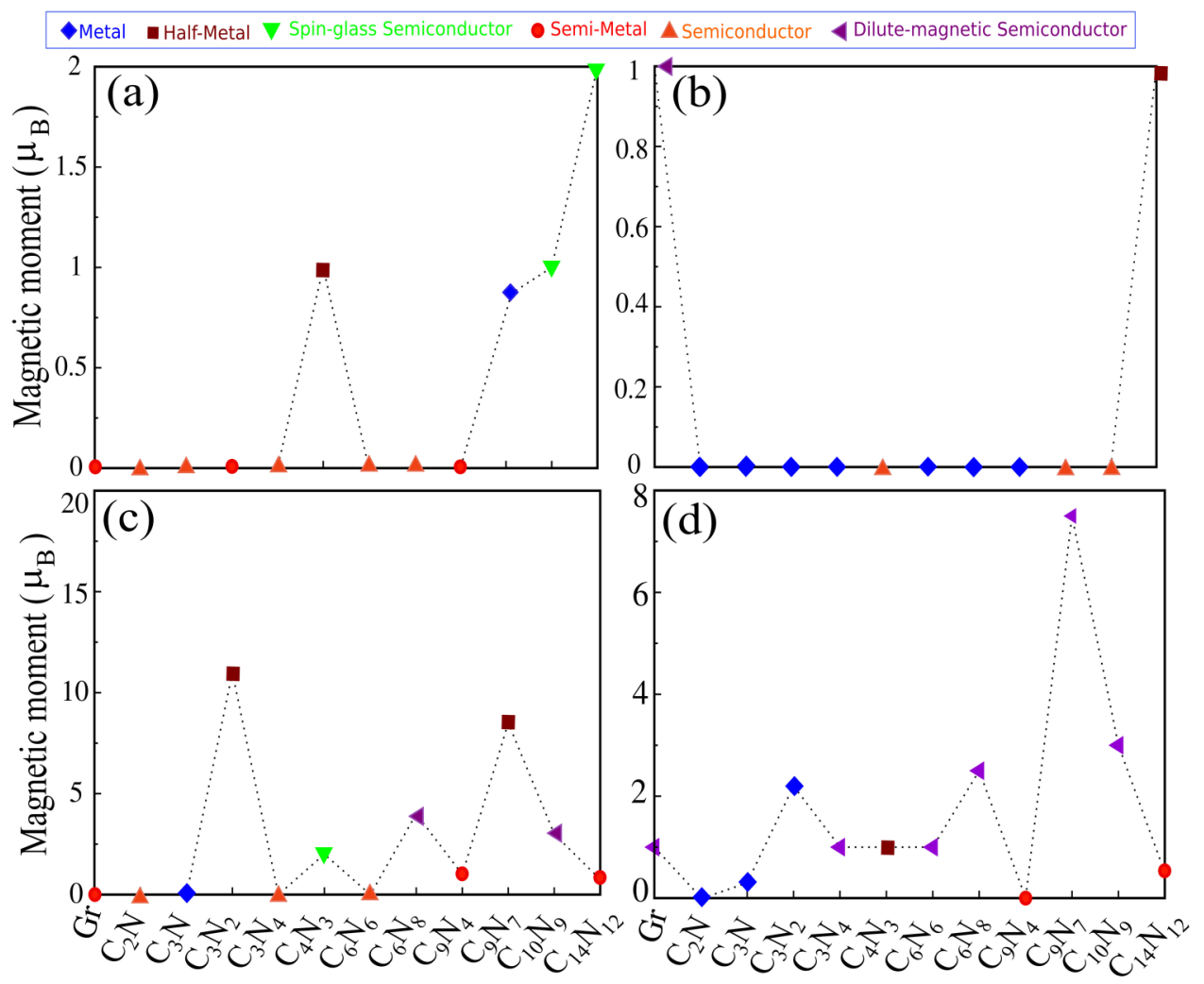

FIG. 11. Variation of magnetic moment of (a) 2DCN, (b) H-adsorbed 2DCN, (c) $\mathrm{H}$-substituted 2DCN, and (d) N-vacancy $2 \mathrm{DCN}$. 
are shown in Figs. 10(a)-10(d) and Figs. 11(a)-11(d). Our result shows that the electronic structure of pristine $2 \mathrm{DCN}$ nanosheets is modified and exhibits a diversity of electronic properties including metal, semimetal, half-metal, ferromagnetic-metal, semiconductor, spin-glass semiconductor, and insulator.

\section{SUBSTITUTION OF N BY C}

The electronic band structures with the corresponding DOS and PDOS of $\mathrm{N}$ substituted by $\mathrm{C}$ in different 2DCN nanosheets are shown in Figs. 12 and 13. The optimized atomic structures and difference charge densities are shown as the insets. The substitution of $\mathrm{N}$ with $\mathrm{C}$ modifies the electronic structure and gives rise to localized states in the energy bandgap. The C-substituted $\mathrm{C}_{3} \mathrm{~N}_{2}, \mathrm{C}_{3} \mathrm{~N}_{4}$, $\mathrm{C}_{4} \mathrm{~N}_{3}$, and $\mathrm{C}_{9} \mathrm{~N}_{7}$ exhibit the ferromagnetic-metal character, and spin-splitting occurs in the $\uparrow$ and $\downarrow$ spin channels and induce, respectively, $0.2,0.6,0.5$, and $1.3 \mu_{B}$ magnetic moments in the ground state. From PDOS, we see that the metallic state is generated by the hybridization of the N/C- $p_{z}\left(\mathrm{C}_{3} \mathrm{~N}_{2}\right)$, N/C- $p_{x, y}\left(\mathrm{C}_{3} \mathrm{~N}_{4}\right.$, $\left.\mathrm{C}_{4} \mathrm{~N}_{3}\right)$, and N/C-s, $p_{x, y, z}\left(\mathrm{C}_{9} \mathrm{~N}_{7}\right)$ orbitals, while C-substituted $\mathrm{C}_{3} \mathrm{~N}$ and $\mathrm{C}_{4} \mathrm{~N}$ becomes a metal because we observe a band crossing at $E_{F}$. Both $\uparrow$ and $\downarrow$ spin bands overlap, and thus there is no spinpolarized state. From the calculated PDOS, we see that the impurity states are mainly from the hybridization of the N/C- $p_{z}$ orbitals. For the C-substituted $\mathrm{C}_{2} \mathrm{~N}, \mathrm{C}_{6} \mathrm{~N}_{6}$, and $\mathrm{C}_{6} \mathrm{~N}_{8}$, the degeneracy of both the $\uparrow$ and $\downarrow$ spin channels is broken and become a dilute-magnetic semiconductor with $1 \mu_{B}$ magnetic moment. The direct bandgap of $\mathrm{C}_{\mathrm{N}}-\mathrm{C}_{2} \mathrm{~N}$ is $1.6 \mathrm{eV}$, while the VBM and CBM are located at the $\Gamma$ point. For the $\mathrm{C}-\mathrm{C}_{2} \mathrm{~N}$, the VBM mainly originates from the hybridization of $\mathrm{C} / \mathrm{N}-s, p_{x, y}$, while the $\mathrm{CBM}$ comes from $\mathrm{C} / \mathrm{N}-s, p_{z}$ in $\uparrow$ spin channel. While the $\mathrm{C}_{\mathrm{N}}-\mathrm{C}_{6} \mathrm{~N}_{6}\left(\mathrm{C}_{\mathrm{N}}-\mathrm{C}_{6} \mathrm{~N}_{8}\right)$, have a direct (indirect) bandgap of $1.5 \mathrm{eV}(1.3 \mathrm{eV})$ and an indirect gap of $1.8 \mathrm{eV}$ (direct $1.3 \mathrm{eV}$ ) in the $\uparrow$ and $\downarrow$ spin channels, respectively. The VBM of $\mathrm{C}_{6} \mathrm{~N}_{8}$ mainly originates from $\mathrm{C} / \mathrm{N}-p_{x, y}$ in $\uparrow$ spin channel, while the CBM originates from C-s, $p_{x, y}$ in the $\downarrow$ spin channel. $\mathrm{C}_{\mathrm{N}}-\mathrm{C}_{9} \mathrm{~N}_{4}$, is a dilute-magnetic semiconductor and induce $1 \mu_{B}$ magnetic moment. A nontrivial direct bandgap of 70 and $100 \mathrm{meV}$ in the $\uparrow$ spin channel, while the VBM and CBM are located between $\Gamma-\mathrm{K}$ points. We see in the $\downarrow$ spin channel, $30 \mathrm{meV}$ and $50 \mathrm{meV}$ nontrivial indirect bandgap and the VBM and $\mathrm{CBM}$ are located at the $\mathrm{K}$ and $\Gamma$ points, respectively. $\mathrm{C}_{\mathrm{N}}-\mathrm{C}_{10} \mathrm{~N}_{9}$, becomes a direct semiconductor with a $0.7 \mathrm{eV}$ bandgap and the VBM mainly originates from the hybridization of $\mathrm{C}-p_{z}$ with the $\mathrm{C} / \mathrm{N}-p_{x, y, z}$ orbital, while the $\mathrm{CBM}$ is built from $\mathrm{C}-p_{x, y, z}$.

$\mathrm{C}_{\mathrm{N}}-\mathrm{C}_{14} \mathrm{~N}_{12}$ turns into a spin-glass semiconductor with $1 \mu_{B}$ magnetic moment. The $\uparrow$ spin channel is a direct semiconductor

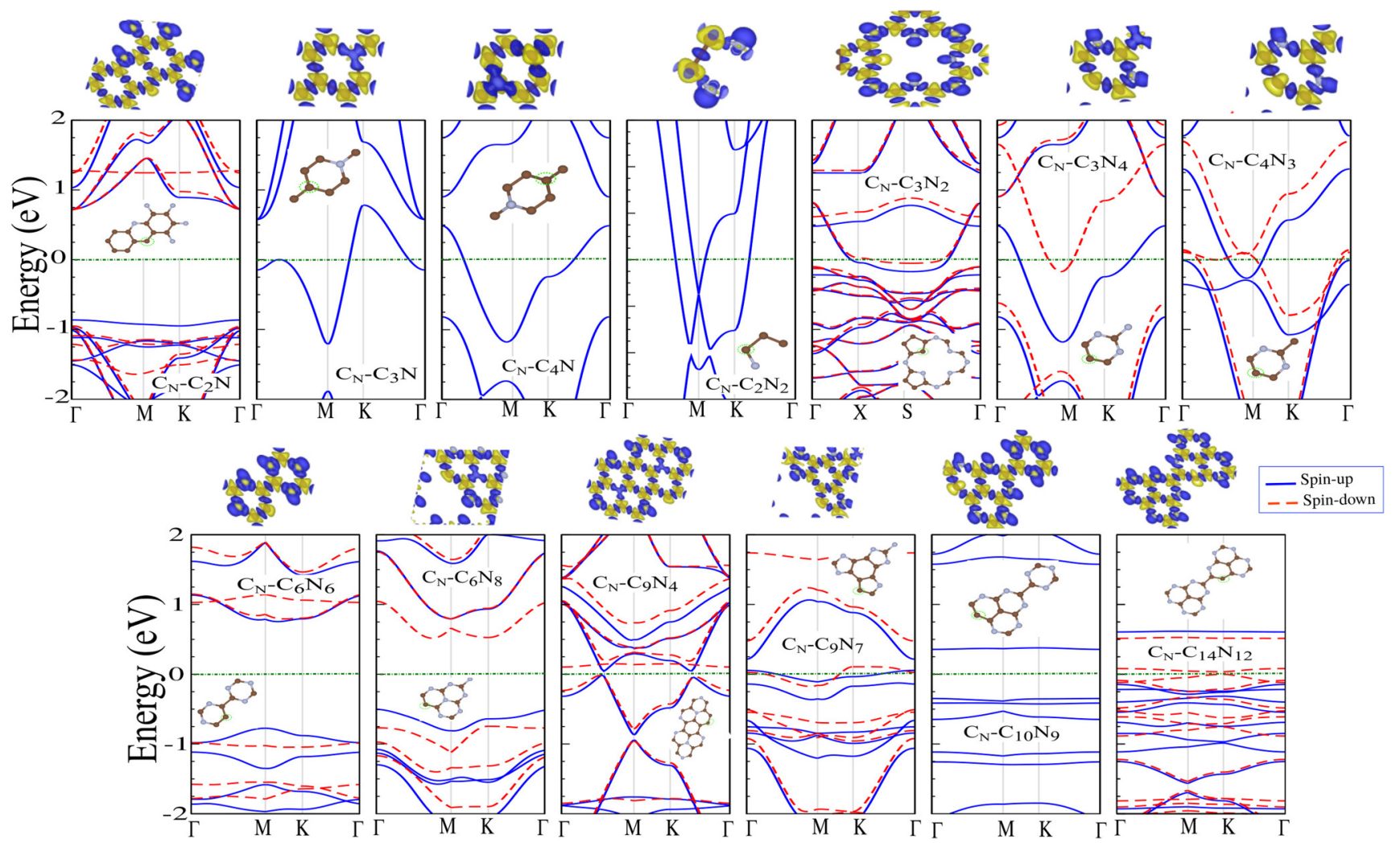

FIG. 12. Electronic band structure of $\mathrm{C}$-substituted $2 \mathrm{DCN}$ nanosheets. The insets are the top view of the optimized structures and difference charge densities. The blue and yellow regions represent the charge accumulation and depletion, respectively. The zero of energy is set at the $E_{F}$ indicated by green dashed-dotted lines. 


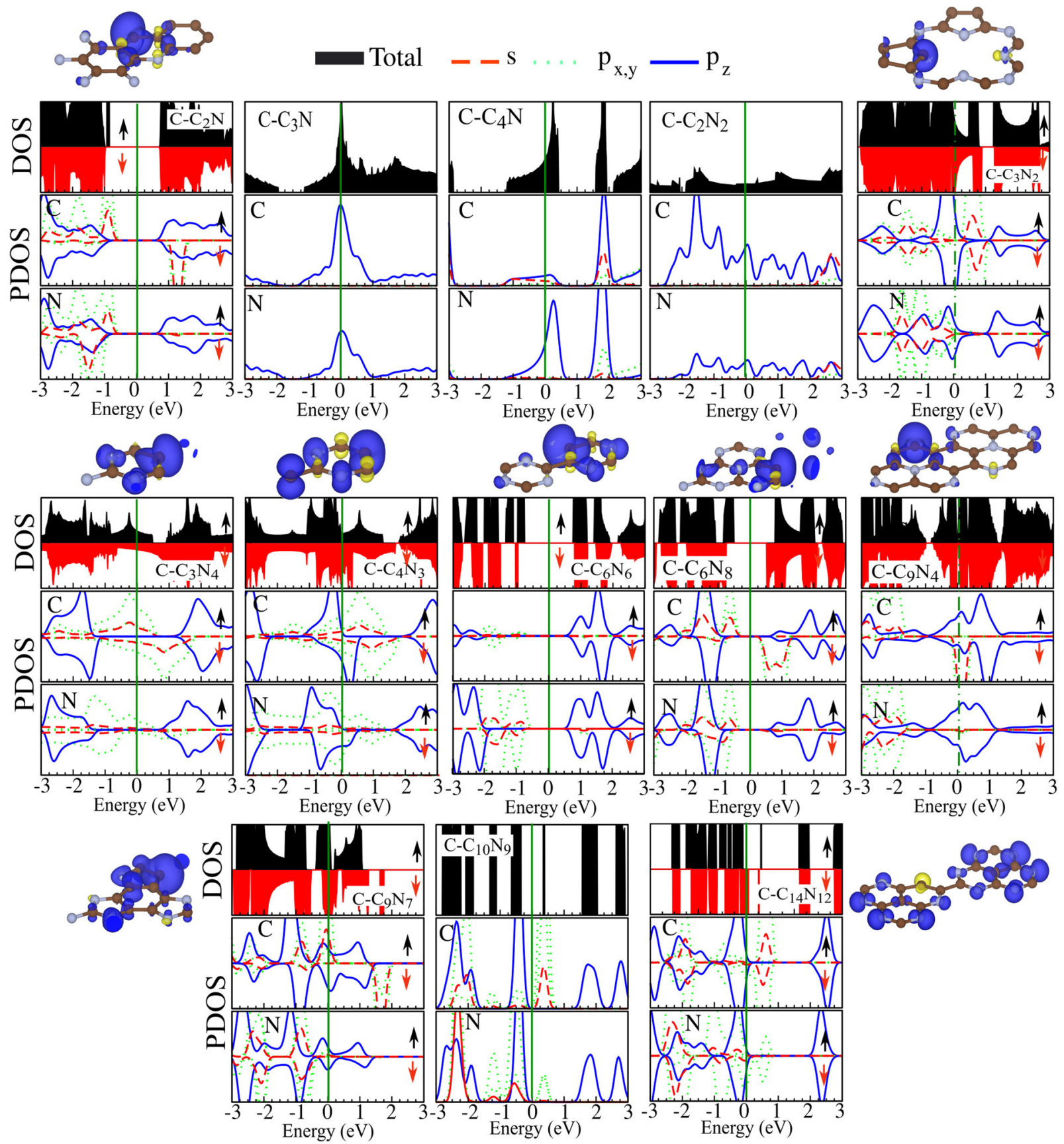

FIG. 13. DOS and PDOS of C-substituted 2DCN nanosheets. The difference spin density is shown in the insets. The blue and yellow regions represent the $\uparrow$ and $\downarrow$ spin directions, respectively. The zero of energy is set at $E_{F}$ indicated by green dashed-dotted vertical lines.

with a $0.8 \mathrm{eV}$ bandgap, while in the $\downarrow$ spin channel, the Dirac-point is eliminated and there is the opening of a $40 \mathrm{meV}$ nontrivial bandgap at $E_{F}$. The VBM mainly originates from the hybridization of $\mathrm{C} / \mathrm{N}-p_{x, y, z}$, while the $\mathrm{CBM}$ comes from $\mathrm{C}-p_{x, y}$ at the $\uparrow$ spin channel. We see that the optimized structures of C-substituted $2 \mathrm{DCN}$ do not have any local deformation. The difference charge density is shown in Fig. 12 as insets. We note there is a charge accumulation in the region between $\mathrm{C}$-substituted atoms and the 
neighboring atoms, giving a strongly covalent bond character in the formed substituted $\mathrm{C}-\mathrm{C}$ or $\mathrm{C}-\mathrm{N}$ bonds. To further clearly understand the magnetic states of the doped systems, the difference spin density is plotted in Fig. 13. The blue and yellow regions represent the $\uparrow$ and $\downarrow$ spin states, respectively. The order of magnetic coupling in $\mathrm{C}_{3} \mathrm{~N}_{4}$ and $\mathrm{C}_{9} \mathrm{~N}_{7}$ is ferromagnetic, while the other magnetic structures exhibit antiferromagnetic interaction. The magnetic moment results from the $\mathrm{C}$ atom and partly from the neighbor $\mathrm{C}$ and $\mathrm{N}$ atoms, and the spin density is entirely localized at the C-substituted impurity.

\section{CONCLUSION}

Two-dimensional carbon-nitride (2DCN) nanomaterials have emerged recently as a prominent member of nanomaterials beyond graphene. In summary, by employing extensive first-principles calculations, we investigated the structural, electronic and magnetic properties of $2 \mathrm{DCN}$ nanosheets of already synthesized $\left(\mathrm{C}_{2} \mathrm{~N}, \mathrm{C}_{3} \mathrm{~N}\right.$, $\mathrm{C}_{3} \mathrm{~N}_{4}, \mathrm{C}_{4} \mathrm{~N}_{3}, \mathrm{C}_{6} \mathrm{~N}_{6}$, and $\left.\mathrm{C}_{6} \mathrm{~N}_{8}\right)$ as well as predict novel one $\left(\mathrm{C}_{3} \mathrm{~N}_{2}\right.$, $\mathrm{C}_{9} \mathrm{~N}_{4}, \mathrm{C}_{9} \mathrm{~N}_{7}, \mathrm{C}_{10} \mathrm{~N}_{9}$, and $\mathrm{C}_{14} \mathrm{~N}_{12}$ ). Energy-band structure calculations show that $2 \mathrm{DCN}$ gives rise to diverse electronic properties including semimetal $\left(\mathrm{C}_{3} \mathrm{~N}_{2}, \mathrm{C}_{4} \mathrm{~N}\right.$, and $\left.\mathrm{C}_{9} \mathrm{~N}_{4}\right)$, half-metal $\left(\mathrm{C}_{4} \mathrm{~N}_{3}\right)$, ferromagnetic-metal $\left(\mathrm{C}_{9} \mathrm{~N}_{7}\right)$, semiconductor $\left(\mathrm{C}_{2} \mathrm{~N}, \mathrm{C}_{3} \mathrm{~N}, \mathrm{C}_{3} \mathrm{~N}_{4}\right.$, $\mathrm{C}_{6} \mathrm{~N}_{6}$, and $\left.\mathrm{C}_{6} \mathrm{~N}_{8}\right)$, spin-glass semiconductor $\left(\mathrm{C}_{10} \mathrm{~N}_{9}\right.$ and $\left.\mathrm{C}_{14} \mathrm{~N}_{12}\right)$, and insulator $\left(\mathrm{C}_{2} \mathrm{~N}_{2}\right)$. We showed how point defects of vacancies, substitutions, and interstitial impurities modify the electronic properties. Furthermore, the effects due to adsorption and substitution of hydrogen atoms as well as $\mathrm{N}$-vacancy defects are investigated. Our results show that, in doing so, the electronic and magnetic properties can be adjustable and allow to tune the bandgap and magnetism. Tunable magnetism and bandgap in 2DCN nanosheets is highly desirable for its use in nanoscale optoelectronic devices.

\section{SUPPLEMENTARY MATERIAL}

See the supplementary material for the tuning of novel electronic and magnetic properties by hydrogenation, atom substitution, and defect engineering.

\section{ACKNOWLEDGMENTS}

This work was supported by the FLAG-ERA project 2DTRANS and the Flemish Science Foundation (FWO-Vl). In addition, we acknowledge the OpenMX team for OpenMX code. We are thankful for comments by Mohammad Nakhaee from the Department of Physics at the University of Antwerp.

\section{REFERENCES}

${ }^{1}$ J. Li, W. Cui, Y. Sun, Yi. Chu, W. Cen, and F. Dong, "Directional electron delivery via a vertical channel between $\mathrm{g}-\mathrm{C}_{3} \mathrm{~N}_{4}$ layers promotes photocatalytic efficiency," J. Mater. Chem. A 5, 9358-9364 (2017).

${ }^{\mathbf{2}}$ Y. Zheng, J. Liu, J. Liang, M. Jaroniec, and S. Z. Qiao, "Graphitic carbon nitride materials: Controllable synthesis and applications in fuel cells and photocatalysis," Energy Environ. Sci. 5, 6717-6731 (2012).

${ }^{3}$ A. Thomas, A. Fischer, F. Goettmann, M. Antonietti, J.-O. Müller, R. Schlögl, and J. M. Carlsson, "Graphitic carbon nitride materials: Variation of structure and morphology and their use as metal-free catalysts," J. Mater. Chem. 18, 4893 (2008).
${ }^{4}$ Y. Zheng, Y. Jiao, J. Chen, J. Liu, J. Liang, A. Du, W. Zhang, Z. Zhu, S. C. Smith, M. Jaroniec, G. Q. (Max) Lu, and S. Z. Qiao, "Nanoporous graphitic- $\mathrm{C}_{3} \mathrm{~N}_{4}$ @carbon metal-free electrocatalysts for highly efficient oxygen reduction," J. Am. Chem. Soc. 133, 20116-20119 (2011).

${ }^{5}$ S. M. Lyth, Y. Nabae, N. M. Islam, S. Kuroki, M. Kakimoto, and S. Miyata, "Electrochemical oxygen reduction activity of carbon nitride supported on carbon black," J. Electrochem. Soc. 158, B194-B201 (2011).

${ }^{6}$ S. M. Lyth, Y. Nabae, S. Moriya, S. Kuroki, M. A. Kakimoto, J. I. Ozaki, and S. Miyata, "Carbon nitride as a nonprecious catalyst for electrochemical oxygen reduction," J. Phys. Chem. C 113, 20148-20151 (2009).

${ }^{7}$ M. Makaremi, S. Grixti, K. T. Butler, G. A. Ozin, and C. V. Singh, "Band engineering of carbon nitride monolayers by $\mathrm{N}$-type, P-type, and isoelectronic doping for photocatalytic applications," ACS Appl. Mater. Interfaces 10, 11143-11151 (2018).

${ }^{8}$ A. Rajabpour, S. Bazrafshan, and S. Volz, "Carbon-nitride 2D nanostructures: Thermal conductivity and interfacial thermal conductance with the silica substrate," Phys. Chem. Chem. Phys. 21, 2507-2512 (2019).

${ }^{9}$ M. Javeed, L. E. Kwang, J. Minbok, S. Dongbin, J. In-Yup, J. Sun-Min, C. Hyun-Jung, S. Jeong-Min, B. Seo-Yoon, S. So-Dam, P. Noejung, O. J. Hak, S. Hyung-Joon, and B. Jong-Beom, "Nitrogenated holey two-dimensional structures," Nat. Commun. 6, 6486 (2015).

${ }^{10}$ J. Mahmood, E. K. Lee, M. Jung, D. Shin, H. J. Choi, J. M. Seo, S. M. Jung, D. Kim, F. Li, M. S. Lah, N. Park, H. J. Shin, J. H. Oh, and J. B. Baek, "Two-dimensional polyaniline $\left(\mathrm{C}_{3} \mathrm{~N}\right)$ from carbonized organic single crystals in solid state," Proc. Natl. Acad. Sci. U.S.A. 113, 7414-7419 (2016).

${ }^{11}$ B. Mortazavi, O. Rahaman, T. Rabczuk, and L. F. C. Pereira, "Thermal conductivity and mechanical properties of nitrogenated holey graphene," Carbon 106, 1-8 (2016).

${ }^{12} \mathrm{~B}$. Mortazavi, "Ultra high stiffness and thermal conductivity of graphene like $\mathrm{C}_{3} \mathrm{~N}$," Carbon 118, 25-34 (2017).

${ }^{13}$ A. Bafekry, S. F. Shayesteh, and F. M. Peeters, " $\mathrm{C}_{3} \mathrm{~N}$ monolayer: Exploring the emerging of novel electronic and magnetic properties with adatom adsorption, functionalizations, electric field, charging and strain," J. Phys. Chem. C 123, 12485-12499 (2019).

${ }^{14}$ M. Makaremi, B. Mortazavi, and C. V. Singh, "Adsorption of metallic, metalloidic, and nonmetallic adatoms on two-dimensional $\mathrm{C}_{3} \mathrm{~N}$," Phys. Chem. C 121, 18575-18583 (2017).

${ }^{15}$ A. Bafekry, M. Ghergherehchi, S. Farjami Shayesteh, and F. M. Peeters, "Adsorption of molecules on $\mathrm{C}_{3} \mathrm{~N}$ nanosheet: A first-principles calculations," Chem. Phys. 526, 110442 (2019).

${ }^{16}$ M. B. Tagani, "Electrical and mechanical properties of a fully hydrogenated two-dimensional polyaniline sheet," Comput. Mater. Sci. 153, 126-133 (2018).

${ }^{17}$ M. B. Tagani and S. I. Vishkayi, "Polyaniline $\left(\mathrm{C}_{3} \mathrm{~N}\right)$ nanoribbons: Magnetic metal, semiconductor, and half-metal," J. Appl. Phys. 124, 084304 (2018).

${ }^{18} \mathrm{M}$. D. Esrafili and S. Heydari, "B-doped $\mathrm{C}_{3} \mathrm{~N}$ monolayer: A robust catalyst for oxidation of carbon monoxide," Theor. Chem. Acc. 138, 57 (2019).

${ }^{19}$ M. D. Esrafili and S. Heydari, "Catalytic reduction of nitrous oxide over borondoped $\mathrm{C}_{3} \mathrm{~N}$ monolayers: A DFT study,” Chem. Phys. Lett. 725, 52-58 (2019).

${ }^{20}$ O. Faye, T. Hussain, A. Karton, and J. Szpunar, "Tailoring the capability of carbon nitride $\left(\mathrm{C}_{3} \mathrm{~N}\right)$ nanosheets toward hydrogen storage upon light transition metal decoration," Nanotechnology 30, 75404 (2018).

${ }^{21}$ Zh. Guizhi, L. Kun, S. Qiang, K. Yoshiyuki, and J. Puru, "Lithium-doped triazine-based graphitic $\mathrm{C}_{3} \mathrm{~N}_{4}$ sheet for hydrogen storage at ambient temperature," Comput. Mater. Sci. 81, 275-279 (2014).

${ }^{22} \mathrm{X}$. Li, S. Zhang, and Q. Wang, "Stability and physical properties of a tri-ring based porous g- $\mathrm{C}_{4} \mathrm{~N}_{3}$ sheet," Phys. Chem. Chem. Phys. 15, 7142-7146 (2013).

${ }^{23}$ A. J. Mannix, B. Kiraly, M. C. Hersam, and N. P. Guisinger, "Synthesis and chemistry of elemental 2D materials," Nat. Rev. Chem. 1, 0014 (2017).

${ }^{\mathbf{2 4}}$ A. Du, S. Sanvito, and S. C. Smith, "First-principles prediction of metal-free magnetism and intrinsic half-metallicity in graphitic carbon nitride," Phys. Rev. Lett. 108, 197207 (2012).

${ }^{25} \mathrm{~T}$. Hu, A. Hashmi, and J. Hong, "Transparent half metallic $\mathrm{g}-\mathrm{C}_{4} \mathrm{~N}_{3}$ nanotubes: Potential multifunctional applications for spintronics and optical devices," Sci. Rep. 4, 6059 (2014). 
${ }^{\mathbf{2 6}} \mathrm{A}$. Hashmi and J. Hong, "Metal free half metallicity in 2D system: Structural and magnetic properties of g- $\mathrm{C}_{4} \mathrm{~N}_{3}$ on BN," Sci. Rep. 4, 4374 (2014).

${ }^{27} \mathrm{X}$. Zhang, M. Zhao, A. Wang, X. Wang, and A. Du, "Spin-polarization and ferromagnetism of graphitic carbon nitride materials," J. Mater. Chem. C 1, 6265-6270 (2013).

${ }^{\mathbf{2 8}} \mathrm{Q}$. Guo, Q. Yang, Ch. Yi, L. Zhu, and Y. Xie, "Synthesis of carbon nitrides with graphite-like or onion-like lamellar structures via a solvent-free route at low temperatures," Carbon 43, 1386-1391 (2005).

${ }^{29} \mathrm{~J}$. Li, C. Cao, J. Hao, H. Qiu, Y. Xu, and H. Zhu, "Self-assembled onedimensional carbon nitride architectures," Diam. Relat. Mater. 15, 1593-1600 (2006).

${ }^{30} \mathrm{H}$. Qiu, Z. Wang, and X. Sheng, "First-principles prediction of an intrinsic half-metallic graphitic hydrogenated carbon nitride," Phys. Lett. A 377, 347-350 (2013).

${ }^{31}$ A. Wang, X. Zhang, and M. Zhao, "Topological insulator states in a honeycomb lattice of s-triazines," Nanoscale 6, 11157-11162 (2014).

${ }^{32}$ V. Arkady, J. P. Rabe, U. Kaiser, A. I. Cooper, A. Thomas, M. J. Bojdys, G. Algara-Siller, N. Severin, S. Y. Chong, T. Björkman, R. G. Palgrave, A. Laybourn, M. Antonietti, Y. Z. Khimyak, and A. V. Krasheninnikov, "Triazine-based graphitic carbon nitride: A two-dimensional semiconductor," Angew. Chem. 126, 7580-7585 (2014).

${ }^{33}$ C. Xu, G. Luo, Q. Liu, J. Zheng, Zh. Zhang, Sh. Nagase, Zh. Gao, and J. Lu, "Giant magnetoresistance in silicene nanoribbons," Nanoscale 4, 3111-3117 (2012).

${ }^{34}$ Z. Ni, H. Zhong, X. Jiang, R. Quhe, G. Luo, Y. Wang, M. Ye, J. Yang, J. Shi, and $\mathrm{J}$. Lu, "Tunable band gap and doping type in silicene by surface adsorption: Towards tunneling transistors," Nanoscale 6, 7609-7618 (2014).

${ }^{35} \mathrm{~F}$. Banhart, J. Kotakoski, and A. V. Krasheninnikov, "Structural defects in graphene," ACS Nano 5, 26-41 (2011).

${ }^{36} \mathrm{X}$. Peng and R. Ahuja, "Symmetry breaking induced band gap in epitaxial graphene layers on SiC," Nano Lett. 8, 4464-4468 (2008).

37J. Gao, J. Zhang, H. Liu, Q. Zhang, and J. Zhao, "Structures, mobilities, electronic and magnetic properties of point defects in silicene," Nanoscale 5, 9785-9792 (2013).

${ }^{38} \mathrm{~W}$. Hu and J. Yang, "Defects in phosphorene," Phys. Chem. C 119, 20474-20480 (2015)

${ }^{39}$ W. Xiong, C. Xia, T. Wang, J. Du, Y. Peng, X. Zhao, and Y. Jia, "Tuning electronic structures of the stanene monolayer via defects and transitionmetal-embedding: Spin-orbit coupling," Phys. Chem. Chem. Phys. 18, 28759-28766 (2016).

${ }^{40} \mathrm{~A}$. Bafekry, M. Ghergherehchi, and S. Farjami Shayesteh, "Tuning the electronic and magnetic properties of antimonene nanosheets via point defects and external fields: First-principles calculations," Phys. Chem. Chem. Phys. 21, 10552-10566 (2019)

${ }^{41}$ A. Ramasubramaniam and D. Naveh, Mn-doped monolayer $\mathrm{MoS}_{2}$ : An atomically thin dilute magnetic semiconductor," Phys. Rev. B 87, 195201 (2013).

${ }^{42}$ S. R. Naqvi, T. Hussain, W. Luo, and R. Ahuja, "Exploring doping characteristics of various adatoms on single-layer stanene," J. Phys. Chem. C 121, 7667-7676 (2017).

${ }^{43}$ A. Bafekry, B. Mortazavi, and S. F. Shayesteh, "Band gap and magnetism engineering in Dirac half-metallic $\mathrm{Na}_{2} \mathrm{C}$ nanosheet via layer thickness, strain and point defects," J. Magn. Magn. Mater. 491, 165565 (2019).

${ }^{44} \mathrm{M}$. Yagmurcukardes, "Monolayer fluoro-InSe: Formation of a thin monolayer via fluorination of InSe," Phys. Rev. B 100, 024108 (2019).

${ }^{45}$ D. Gao, S. Shi, K. Tao, B. Xia, and D. Xue, "Tunable ferromagnetic ordering in $\mathrm{MoS}_{2}$ nanosheets with fluorine adsorption," Nanoscale 7, 4211-4216 (2015).

${ }^{46}$ A. Bafekry, C. Stampfl, M. Ghergherehchi, and S. Farjami Shayesteh, "A firstprinciples study of the effects of atom impurities, defects, strain, electric field and layer thickness on the electronic and magnetic properties of the $\mathrm{C}_{2} \mathrm{~N}$ nanosheet," Carbon 157, 371-384 (2020).

${ }^{47} \mathrm{~B}$. Akgenc, "New predicted two-dimensional MXenes and their structural, electronic and lattice dynamical properties," Solid State Commun. 303-304, 113739 (2020).
${ }^{48}$ A. Bafekry, M. Ghergherehchi, and S. Farjami Shayesteh, "Tuning the electronic and magnetic properties of antimonene nanosheets via point defects and external fields: first-principles calculations," Phys. Chem. Chem. Phys. 21 10552-10566 (2019).

${ }^{49}$ D. Kiymaz, M. Yagmurcukardes, A. Tomak, H. Sahin, R. T. Senger, F. M. Peeters, H. M. Zareie, and C. Zafer, "Controlled growth mechanism of poly (3-hexylthiophene) nanowires," Nanotechnology 27, 455604 (2016).

${ }^{50}$ A. Bafekry, B. Akgenc, S. Farjami Shayesteh, and B. Mortazavi, "Tunable electronic and magnetic properties of graphene/carbon-nitride van der Waals heterostructures," Appl. Surf. Sci. 144450 (2019).

${ }^{51}$ Z. Kahraman, A. Kandemir, M. Yagmurcukardes, and H. Sahin, "Single-layer Janus-type platinum dichalcogenides and their heterostructures," J. Phys. Chem. C 123, 4549-4557 (2019).

${ }^{52}$ A. Bafekry, S. Farjami Shayesteh, M. Ghergherehchi, and F. M. Peeters, "Tuning the bandgap and introducing magnetism into monolayer $\mathrm{BC}_{3}$ by strain/ defect engineering and adatom/molecule adsorption," J. Appl. Phys. 126, 144304 (2019)

${ }^{53}$ M. Yagmurcukardes, S. Ozen, F. Iyikana, F. M. Peeters, and H. Sahin, "Raman fingerprint of stacking order in $\mathrm{HfS}_{2}-\mathrm{Ca}(\mathrm{OH})_{2}$ heterobilayer," Phys. Rev. B 99, 205405 (2019).

${ }^{54}$ A. Bafekry, C. Stampfl, and S. Shayesteh, "A first-principles study of $\mathrm{C}_{3} \mathrm{~N}$ nanostructures: Control and engineering of the electronic and magnetic properties of nanosheets, tubes and ribbons," ChemPhysChem (2019).

${ }^{55}$ S. V. Badalov, M. Yagmurcukardes, F. M. Peeters, and H. Sahin, "Enhanced stability of single-layer w-gallenene through hydrogenation," J. Phys. Chem. C 122, 28302-28309 (2018)

${ }^{56}$ S. V. Badalov, M. Yagmurcukardes, F. M. Peeters, and H. Sahin, "Enhanced stability of single-layer w-gallenene through hydrogenation," J. Phys. Chem. C 122, 28302-28309 (2018)

${ }^{57}$ S. Chintalapati, L. Shen, Q. Xiong, and Y. P. Feng, "Magnetism in phosphorene: Interplay between vacancy and strain," Appl. Phys. Lett. 107, 072401 (2015).

${ }^{58}$ A. Bafekry, C. Stampfl, S. F. Shayesteh, and F. M. Peeters, "Exploiting the novel electronic and magnetic structure of $\mathrm{C}_{3} \mathrm{~N}$ via functionalization and conformation," Adv. Electr. Mater. (published online).

${ }^{59}$ M. Yagmurcukardes, C. Bacaksiz, R. T. Senger, and H. Sahin, "Hydrogen-induced structural transition in single layer ReS 2 ," 2D Mater. 4, 035013 (2017).

${ }^{60} \mathrm{~T}$. Ozaki, K. Nishio, and H. Kino, "Efficient implementation of the nonequilibrium Green function method for electronic transport calculations," Phys. Rev. B 81, 035116 (2010).

${ }^{61}$ J. P. Perdew, K. Burke, and M. Ernzerhof, "Generalized gradient approximation made simple," Phys. Rev. Lett. 77, 3865-3868 (1996).

${ }^{62} \mathrm{~N}$. Troullier and J. L. Martins, "Efficient pseudopotentials for plane-wave calculations," Phys. Rev. B 43, 1993-2006 (1991).

${ }^{63} \mathrm{~T}$. Ozaki, "Variationally optimized atomic orbitals for large-scale electronic structures," Phys. Rev. B 67, 155108 (2003).

${ }^{64} \mathrm{~T}$. Ozaki and H. Kino, "Numerical atomic basis orbitals from $\mathrm{H}$ to Kr," Phys. Rev. B 69, 195113 (2004)

${ }^{65} \mathrm{H}$. J. Monkhorst and J. D. Pack, "Special points for Brillouin-zone integrations," Phys. Rev. B 13, 5188-5192 (1976).

${ }^{66}$ J. Tersoff and D. R. Hamann, "Theory and application for the scanning tunneling microscope," Phys. Rev. Lett. 50, 1998-2001 (1983).

${ }^{67}$ I. Horcas, R. Fernández, J. M Gómez-Rodríguez, J. Colchero, J. Gómez-Herrero, and A. M. Baro, "WSXM: A software for scanning probe microscopy and a tool for nanotechnology,” Rev. Sci. Instrum. 78, 013705 (2007).

${ }^{68} \mathrm{~L}$. Zhu, Q. Xue, X. Li, T. Wu, Y. Jin, and W. Xing, " $\mathrm{C}_{2} \mathrm{~N}$ : An excellent twodimensional monolayer membrane for He separation," J. Mater. Chem. A 3, 21351-21356 (2015)

${ }^{69}$ Y. Qu, F. Li, H. Zhou, and M. Zhao, "Highly efficient quantum sieving in porous graphene-like carbon nitride for light isotopes separation," Sci. Rep. 6 19952 (2016).

${ }^{70}$ B. Xu, H. Xiang, Q. Wei, J. Q. Liu, Y. D. Xia, J. Yin, and Z. G. Liu, "Two-dimensional graphene-like $\mathrm{C}_{2} \mathrm{~N}$ : An experimentally available porous membrane for hydrogen purification," Phys. Chem. Chem. Phys. 17, 15115-15118 (2015). 
${ }^{71}$ I. Choudhuri and B. Pathak, "Ferromagnetism and half-metallicity in atomically thin holey nitrogenated graphene based systems," Chem. Phys. Chem. 18, 2336-2346 (2107)

${ }^{72}$ D. Mpoutas and L. Tsetseris, "Magnetic two-dimensional $\mathrm{C}_{3} \mathrm{~N}_{2}$ carbonitrides: Semiconductors, metals and half-metals," Phys. Chem. Chem. Phys. 19, 26743-26748 (2017).

${ }^{73} \mathrm{~L}$. Tsetseris, "Functionalization of two-dimensional phthalo-carbonitride with metal atoms," Phys. Chem. Chem. Phys. 18, 26088-26093 (2016).

${ }^{74}$ E. Kroke, M. Schwarz, E. Horath-Bordon, P. Kroll, B. Noll, and A. D. Norman, "Tri-s-triazine derivatives. Part I. From trichloro-tri-s-triazine to graphitic $\mathrm{C}_{3} \mathrm{~N}_{4}$ structures," New J. Chem. 26, 508-512 (2002).

${ }^{75}$ X. Wang, K. Maeda, A. Thomas, K. Takanabe, G. Xin, J. M. Carlsson, K. Domen, and M. Antonietti, "A metal-free polymeric photocatalyst for hydrogen production from water under visible light," Nat. Mater. 8, 76-80 (2008).

${ }^{76}$ G. Liu, P. Niu, S. C. Smith, Zh. Chen, G. Q. (Max) Lu, and H.-M. Cheng, "Unique electronic structure induced high photoreactivity of sulfur-doped graphitic $\mathrm{C}_{3} \mathrm{~N}_{4}$," J. Am. Chem. Soc. 132, 11642-11648 (2010).

${ }^{77}$ K. Srinivasu, B. Modak, and S. K. Ghosh, "Porous graphitic carbon nitride: A possible metal-free photocatalyst for water splitting," J. Phys. Chem. C 118, 26479-26484 (2014).

${ }^{78}$ J. Wirth, R. Neumann, M. Antonietti, and P. Saalfrank, "Adsorption and photocatalytic splitting of water on graphitic carbon nitride: A combined first principles and semiempirical study," Phys. Chem. Chem. Phys. 16, 15917-15926 (2014).

${ }^{79}$ I. Choudhuri, G. Bhattacharyya, S. Kumar, and B. Pathak, "Metal-free half-metallicity in a high energy phase C-doped gh- $\mathrm{C}_{3} \mathrm{~N}_{4}$ system: A high curie temperature planar system," J. Mater. Chem. C 4, 11530-11539 (2016).

${ }^{80}$ S. Sarikurt and F. Ersan, "Phononic stability analysis of two-dimensional carbon nitride monolayers," Marmara J. Pure Appl. Sci. 30(4), 383-387 (2018).

${ }^{81}$ H. Chen, Sh. Zhang, W. Jiang, Ch. Zhang, H. Guo, Zh. Liu, Zh. Wang, F. Liu, and $\mathrm{X}$. Niu, "Prediction of two-dimensional nodal-line semimetals in a carbon nitride covalent network," J. Mater. Chem. A 6, 11252-11259 (2018).

${ }^{82} \mathrm{H}$. Li, H. Hu, Ch. Bao, J. Hua, H. Zhou, X. Liu, X. Liu, and M. Zhao, "Tensile strain induced half-metallicity in graphene-like carbon nitride," Phys. Chem. Chem. Phys. 17, 6028-6035 (2015).

${ }^{83} \mathrm{X}$. Zhang and M. Zhao, "Prediction of quantum anomalous Hall effect on graphene nanomesh," RSC Adv. 5, 9875-9880 (2015).

${ }^{84} \mathrm{X}$. Zhang, A. Wang, and M. Zhao, "Spin-gapless semiconducting graphitic carbon nitrides: A theoretical design from first principles," Carbon $\mathbf{8 4}, 1-8$ (2015).
${ }^{85}$ L. L. Li, X. Kong, O. Leenaerts, X. Chen, B. Sanyal, and F. M. Peeters, "Carbon-rich carbon nitride monolayers with Dirac cones: Dumbbell $\mathrm{C}_{4} \mathrm{~N}$," Carbon 118, 285-290 (2017).

${ }^{86}$ A. H. Castro Neto, F. Guinea, N. M. R. Peres, K. S. Novoselov, and A. K. Geim, "The electronic properties of graphene," Rev. Mod. Phys. 81, 109-162 (2009).

${ }^{87}$ K. S. Novoselov, D. Jiang, F. Schedin, T. J. Booth, V. V. Khotkevich, S. V. Morozov, and A. K. Geim, "Two-dimensional atomic crystals," Proc. Natl. Acad. Sci. U.S.A. 102, 10451-10453 (2005).

${ }^{88} \mathrm{Y}$. Li, Z. Zhou, G. Yu, W. Chen, and Z. Chen, "CO catalytic oxidation on ironembedded graphene: Computational quest for low-cost nanocatalysts," J. Phys. Chem. C 114, 6250-6254 (2010).

${ }^{89}$ A. K. Geim and K. S. Novoselov, "The rise of graphene," Nat. Mater. 6(3), 183-191 (2007).

${ }^{90}$ M. Yagmurcukardes, S. Horzum, E. Torun, F. M. Peeters, and R. Tugrul Senger, "Nitrogenated, phosphorated and arsenicated monolayer holey graphenes," Phys. Chem. Chem. Phys. 18, 3144-3150 (2016).

${ }^{91}$ R. Zhang, B. Li, and J. Yang, "Effects of stacking order, layer number and external electric field on electronic structures of few-layer $\mathrm{C}_{2} \mathrm{~N}-h 2 \mathrm{D}$," Nanoscale 7, 14062-14070 (2015).

${ }^{92} \mathrm{Q}$. Hu, Q. Wu, H. Wang, J. He, and G. Zhang, "First-principles studies of structural and electronic properties of layered $\mathrm{C}_{3} \mathrm{~N}$ phases," Phys. Status Solidi (b) 249, 784-788 (2011).

${ }^{93}$ H. J. Xiang, B. Huang, Z. Y. Li, S.-H. Wei, J. L. Yang, and X. G. Gong, "Ordered semiconducting nitrogen-graphene alloys,” Phys. Rev. X 2, 011003 (2012).

${ }^{94} \mathrm{H}$. Wu, Y. Liu, E. Kan, W. Xu, J. Li, M. Yan, R. Lu, J. Wei, Y. Qian, and Y. Ma, "The diverse electronic properties of $\mathrm{C}_{4} \mathrm{~N}_{3}$ monolayer under biaxial compressive strain: A theoretical study,” Appl. Phys. 49, 295301 (2016).

${ }^{95} \mathrm{X}$. Li, Y. Dai, Y. Ma, Sh. Han, and B. Huang, "Graphene/g- $\mathrm{C}_{3} \mathrm{~N}_{4}$ bilayer: Considerable band gap opening and effective band structure engineering," Phys. Chem. Chem. Phys. 16, 4230-4235 (2014).

${ }^{96}$ O. Leenaerts, H. Peelaers, A. D. Hernández-Nieves, B. Partoens, and F. M. Peeters, "First-principles investigation of graphene fluoride and graphane," Phys. Rev. B 82, 195436 (2010)

${ }^{97}$ M. M. Ugeda, I. Brihuega, F. Guinea, and J. M. Gómez-Rodríguez, "Missing atom as a source of carbon magnetism, "Phys. Rev. Lett. 104, 096804 (2010).

${ }^{98} \mathrm{H}$. A. Jahn and E. Teller, "Stability of polyatomic molecules in degenerate electronic states-I-Orbital degeneracy," Proc. R. Soc. London A 161, 220-235 (1937). 